ISSN 2449-2604

JEL Classification: M19

DOI: 10.46361/2449-2604.8.2.2021.39-61

\section{MIRZA SUKNISHVILI}

Batumi Shota Rustaveli State University, PhD student in Business Administration Georgia, Batumi

E-mail: Mirzasuknishvili@gmail.com https://orcid.org/0000-0003-0365-2226

\section{Edited by:}

June, 2021

Reviewed by:

July, 2021

\section{PROBLEMS OF SUSTAINABLE FOOD SECURITY AND THE NEEDS OF AGRIBUSINESS DEVELOPMENT IN GEORGIA}

The issue of food security and providing it to the population in accordance with the norms of the world medical organizations is not only a socio-political issue, but also of strategic importance for any country. Judging by the official data, judging by the annual volume of production of basic foodstuffs, even half of them do not meet the requirements set by the norms. There is an even greater disproportion in terms of grain production. This is when the country can cover $70 \%$ of its annual needs through domestic production in accordance with proper agrarian development. The same is true of the production of vegetables, horticultural, some single and perennial crops (except grapes, wine and wine materials) and livestock products.

The study found that farmers, entrepreneurs and agricultural workers in the agricultural sector are still similar to smallholder farms, have less contribution to total production, very little cash income and hence the opportunity to expand their activities

Key Words: Food Security, Agribusiness, Supply Chain 
ISSN 2449-2604

JEL Classification: M19

DOI: 10.46361/2449-2604.8.2.2021.39-61

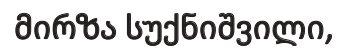

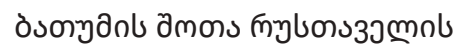

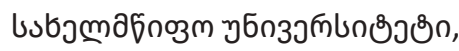

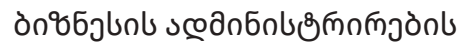

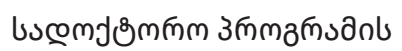

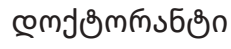

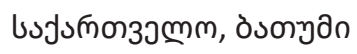

E-mail: Mirzasuknishvili@gmail.com https://orcid.org/0000-0003-0365-

2226

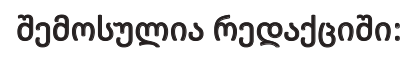

o35olo, 2021

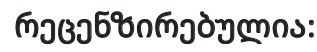

o3molo, 2021

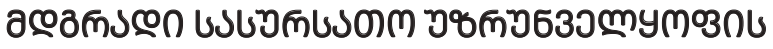

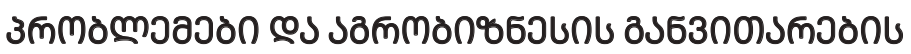

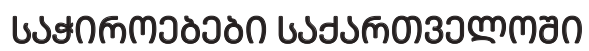

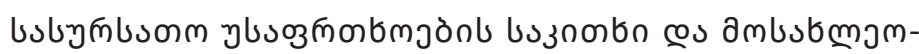

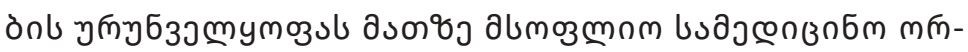

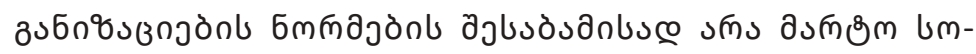

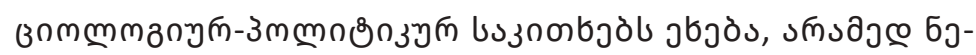

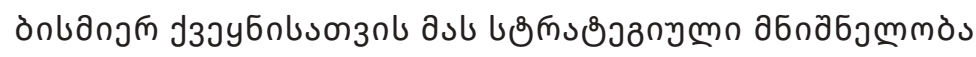

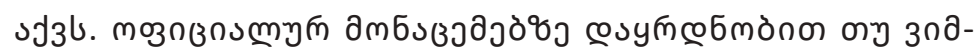

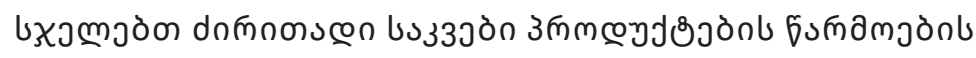

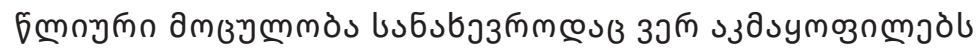

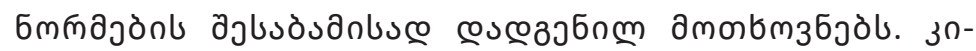

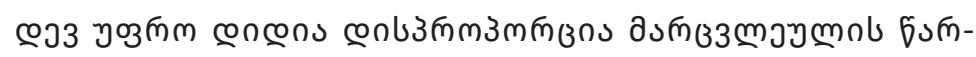

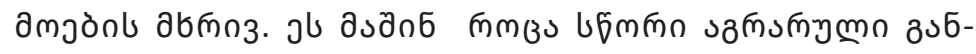

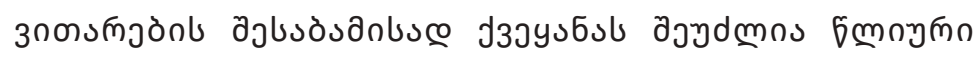

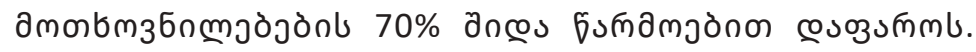

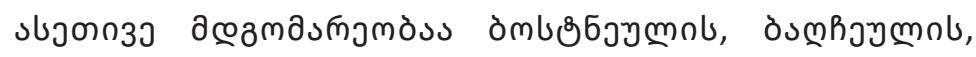

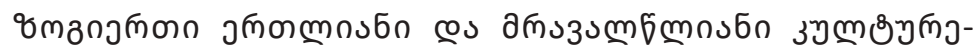

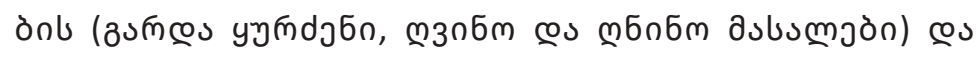

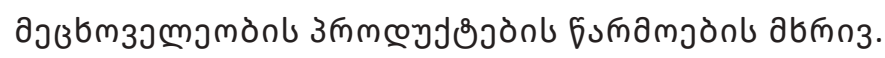

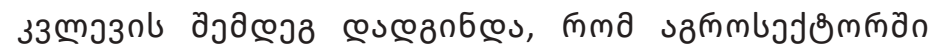

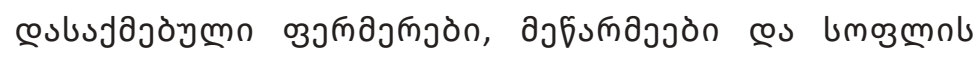

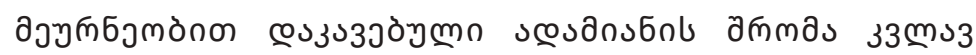

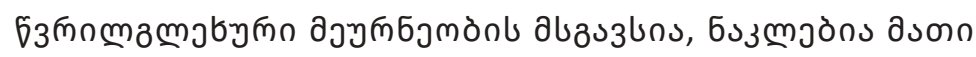

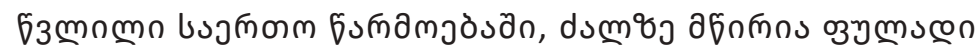

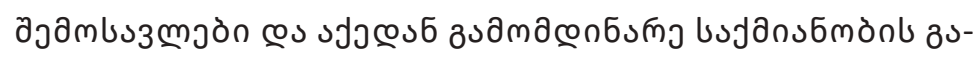

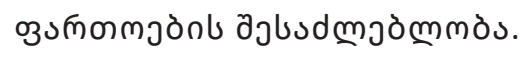

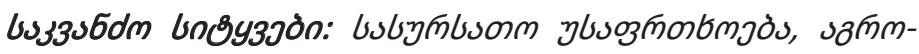
ò 


\section{วอนJ3Sलn}

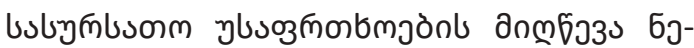

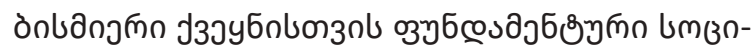

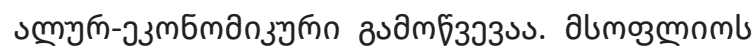

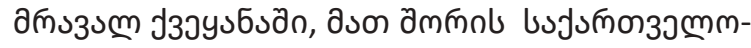

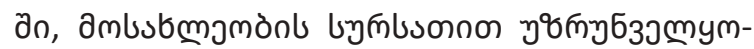

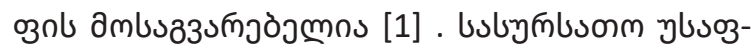

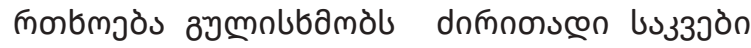

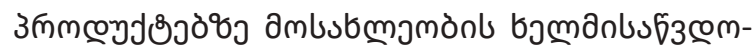
amòsl.

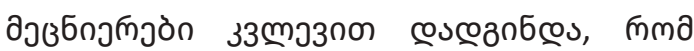

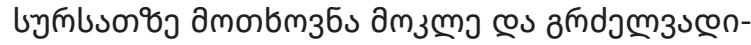

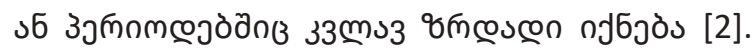

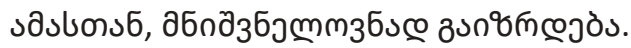

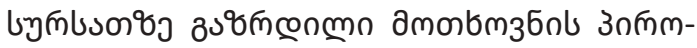

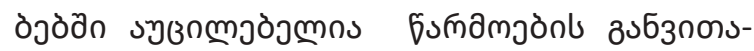

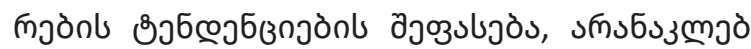

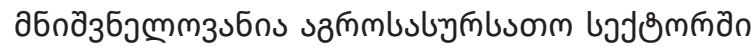

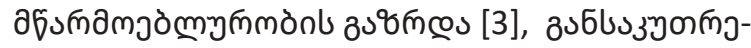

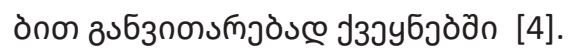

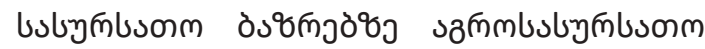

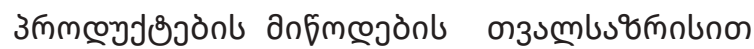

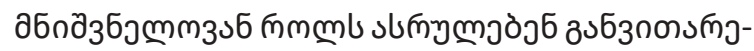

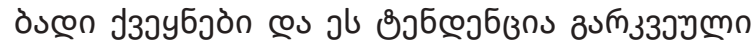

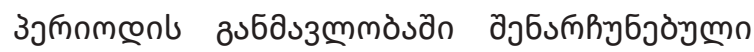

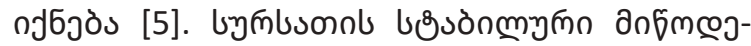

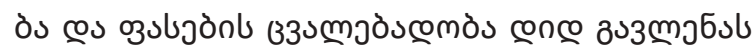

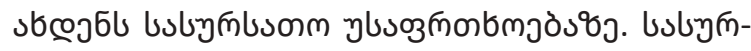

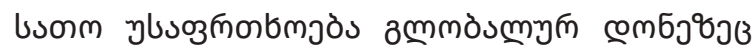

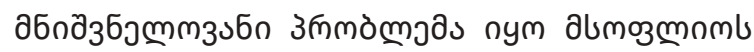

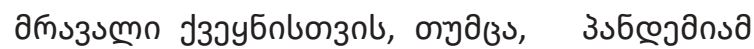

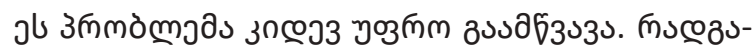

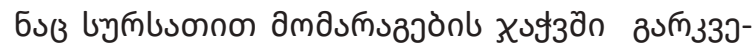

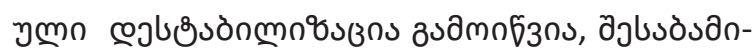

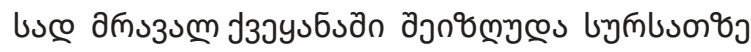

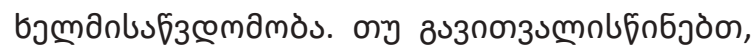

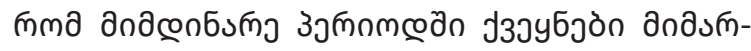

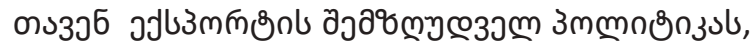

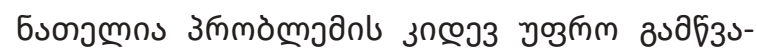

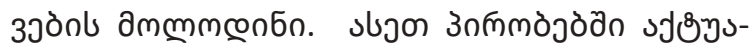

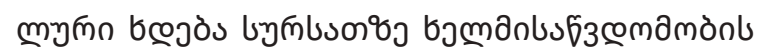

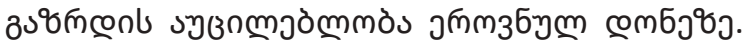

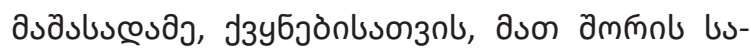

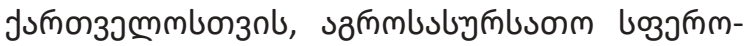

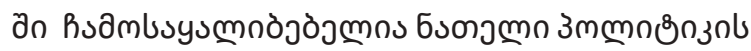

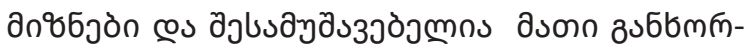

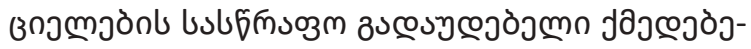
òn.

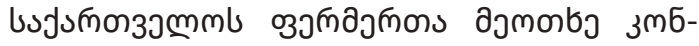

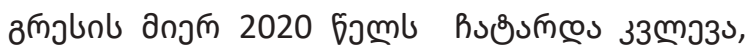

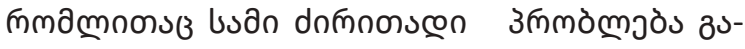

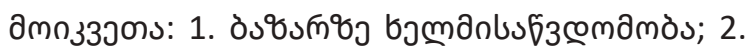

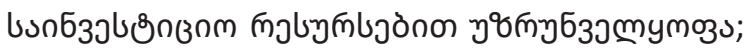

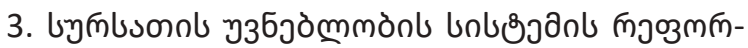

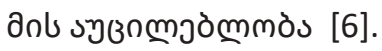

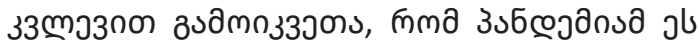

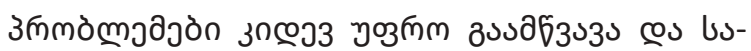

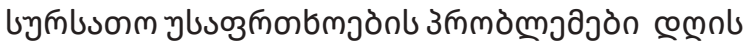

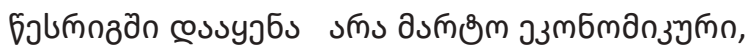
ง

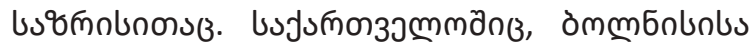

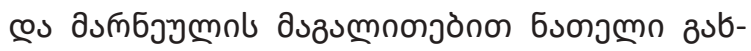
œu, mma bugnmms byńlsonob anfmejònb xug-

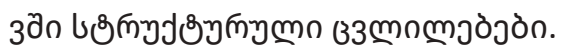

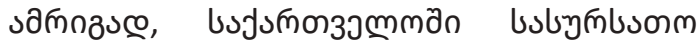

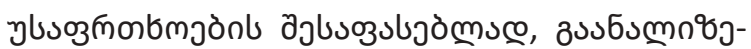

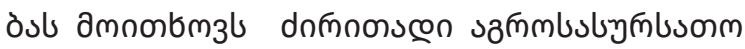

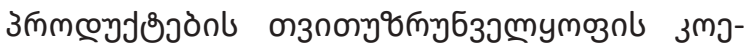

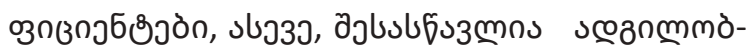

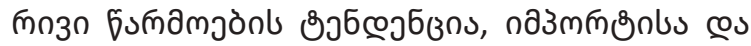

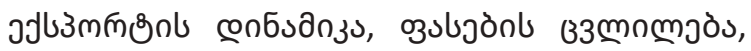

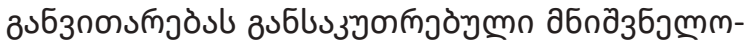

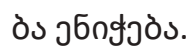

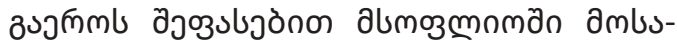

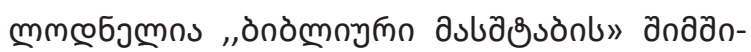

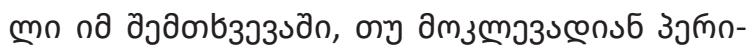

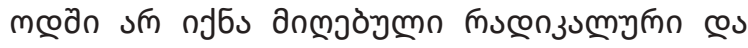

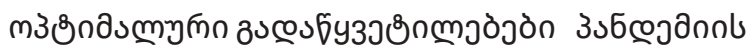

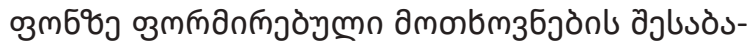

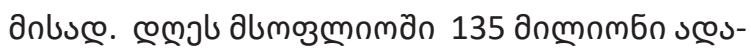

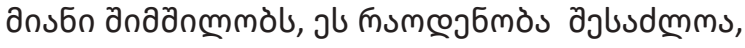

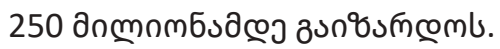




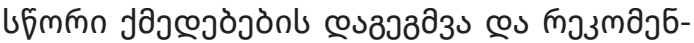

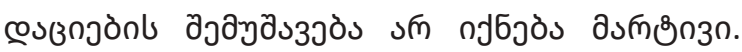

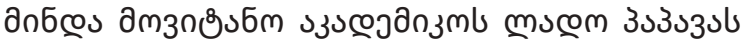

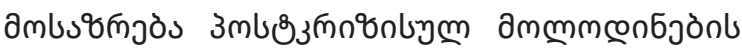

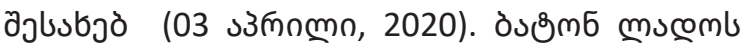

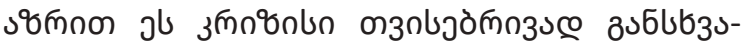

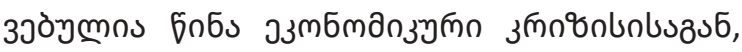

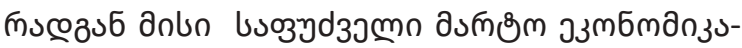
an sm djub.

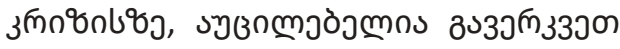

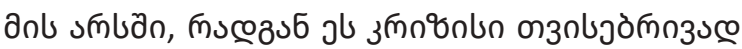

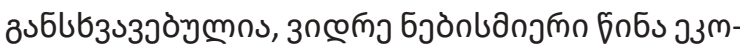

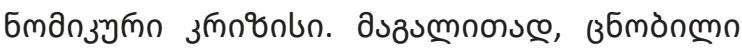

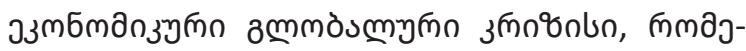

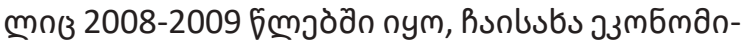

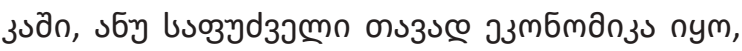

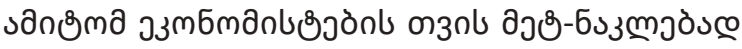

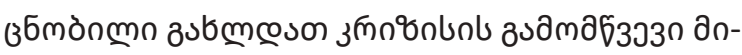

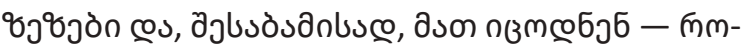

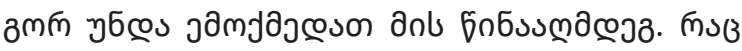

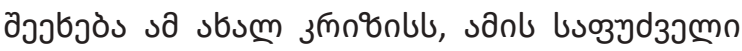
उзmбmanзsव̃n sm daз [7].

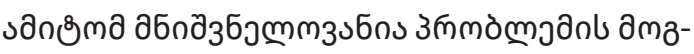

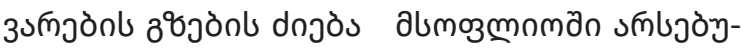

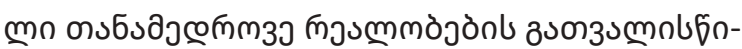

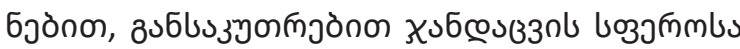

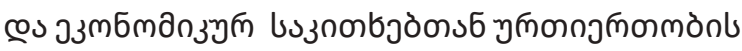

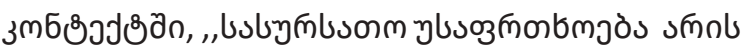

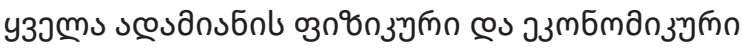

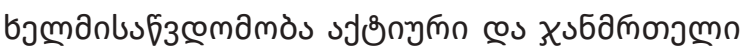

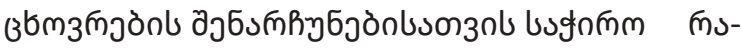

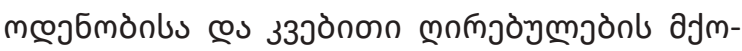

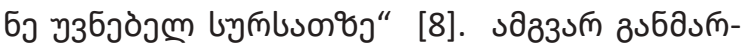

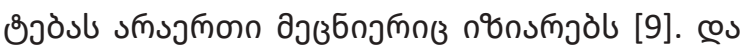

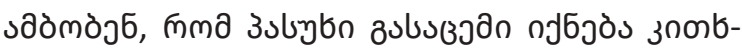

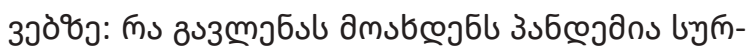

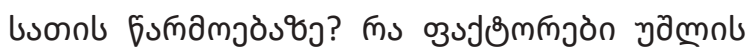

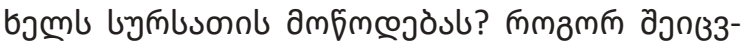

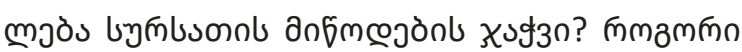

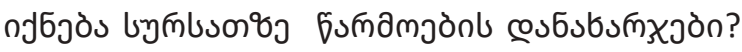

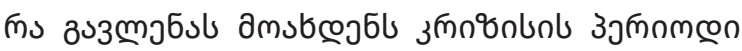

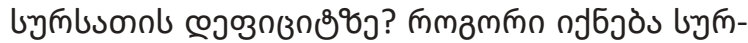

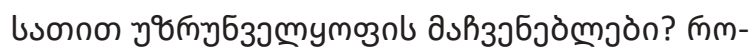

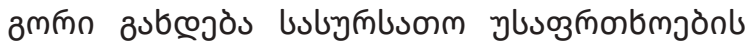

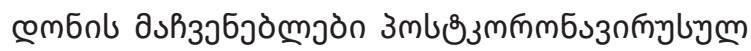

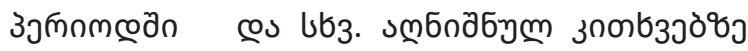

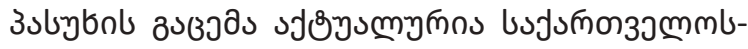

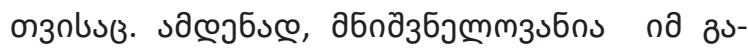

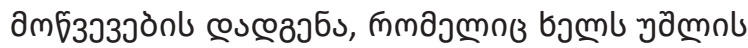

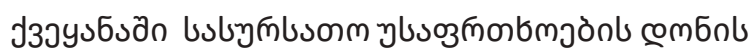

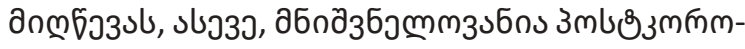

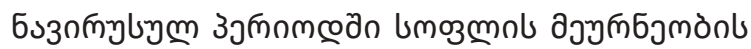

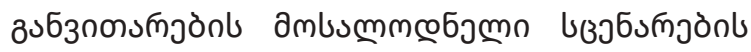

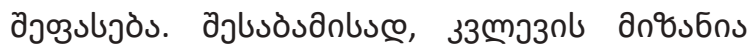

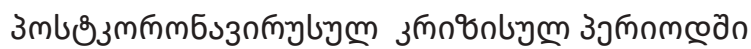

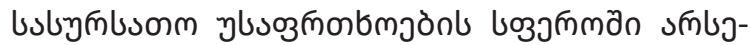

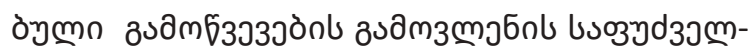

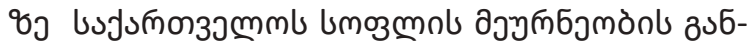

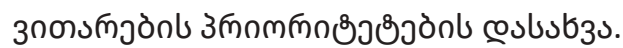

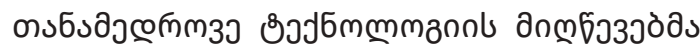

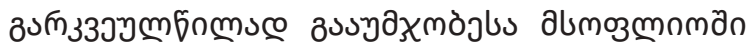

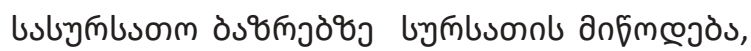

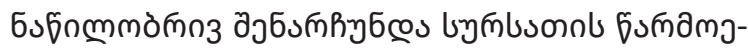

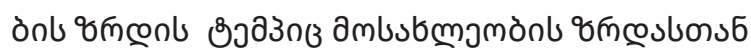

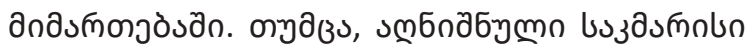

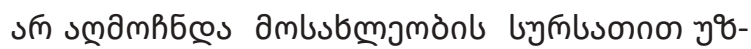

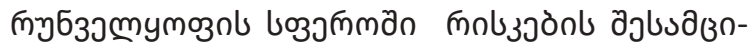
ตృঠ̀mง [10].

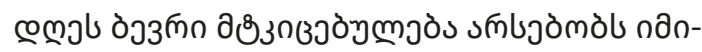

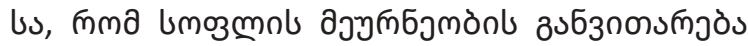

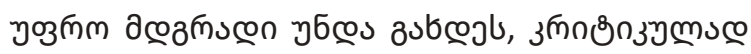

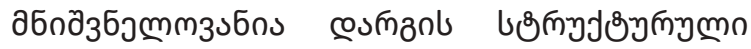

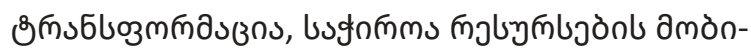

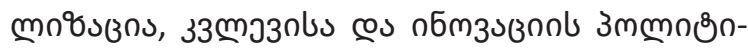
zol bsbumnobjòs [11].

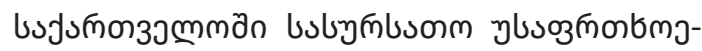

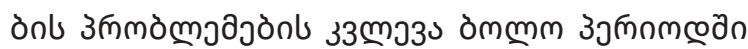

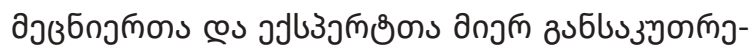

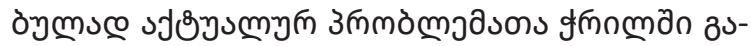

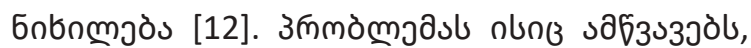

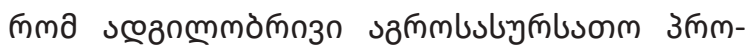

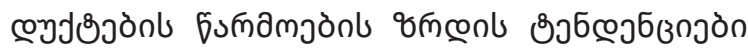




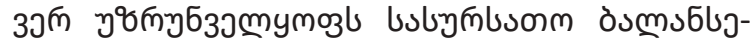

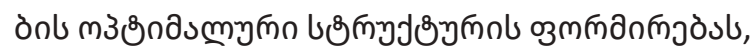

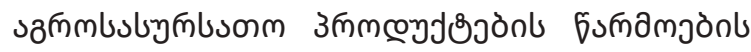

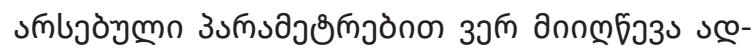

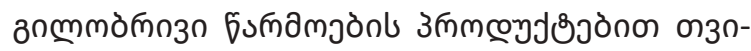

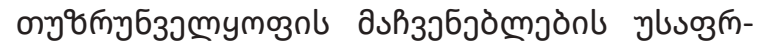

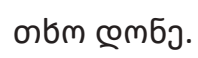

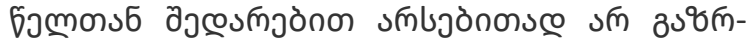

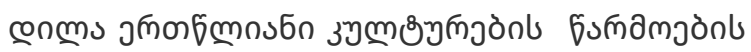

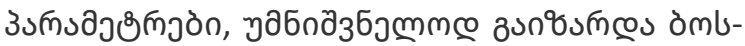

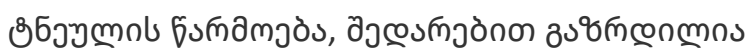

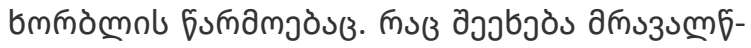

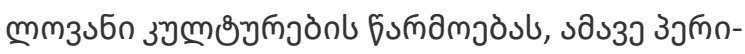

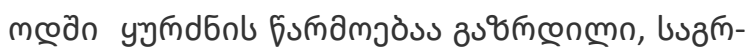

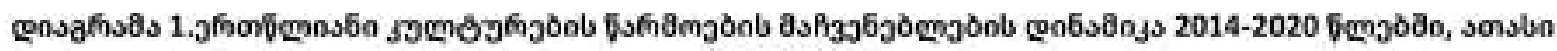 Ŝm5s [13]}

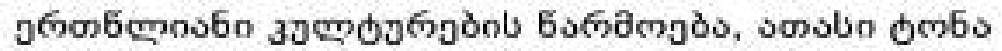

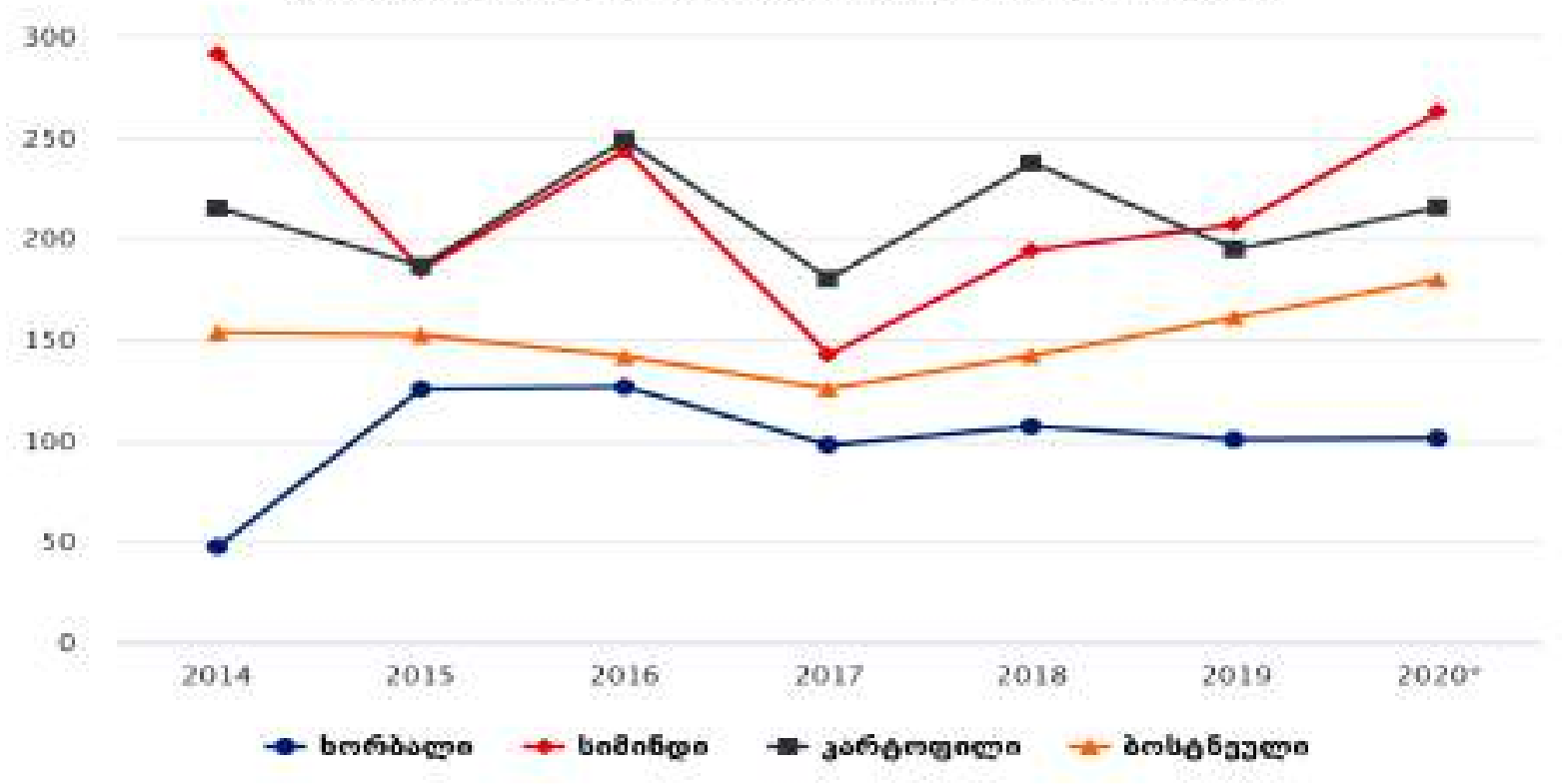

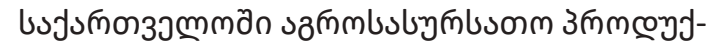

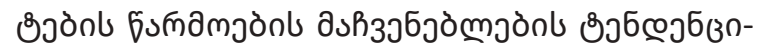

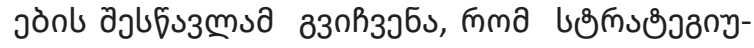

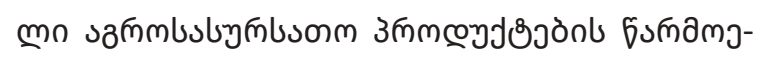

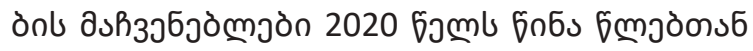

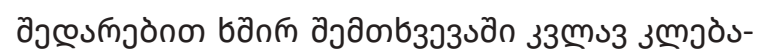

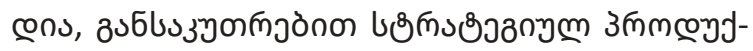
తింరిชว

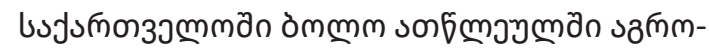

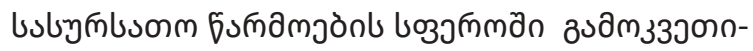

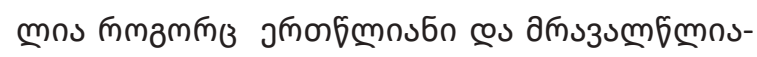

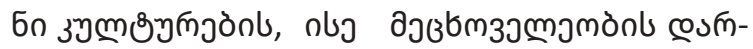

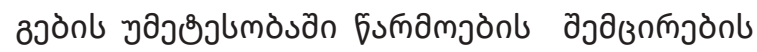

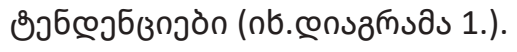

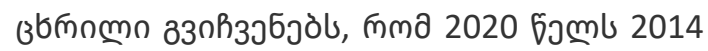

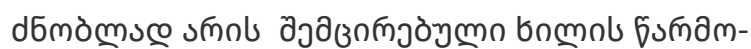

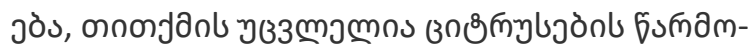

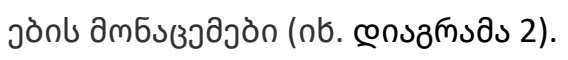

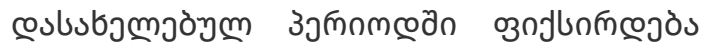

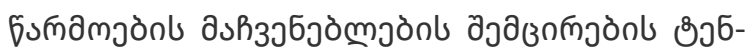

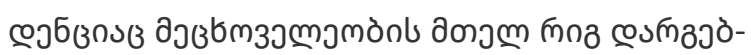

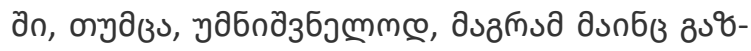

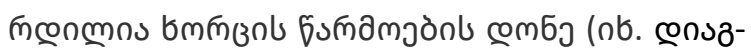
msas 3).

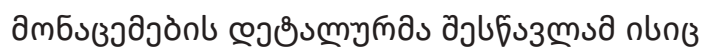

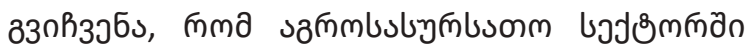

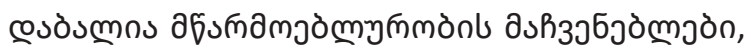

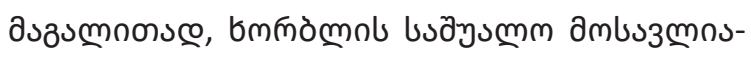

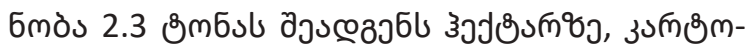




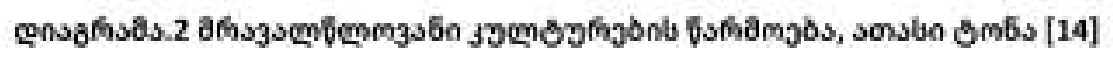

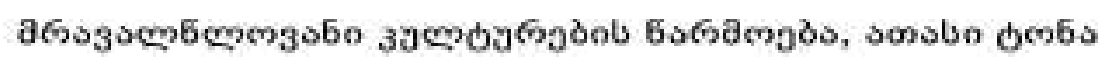

400

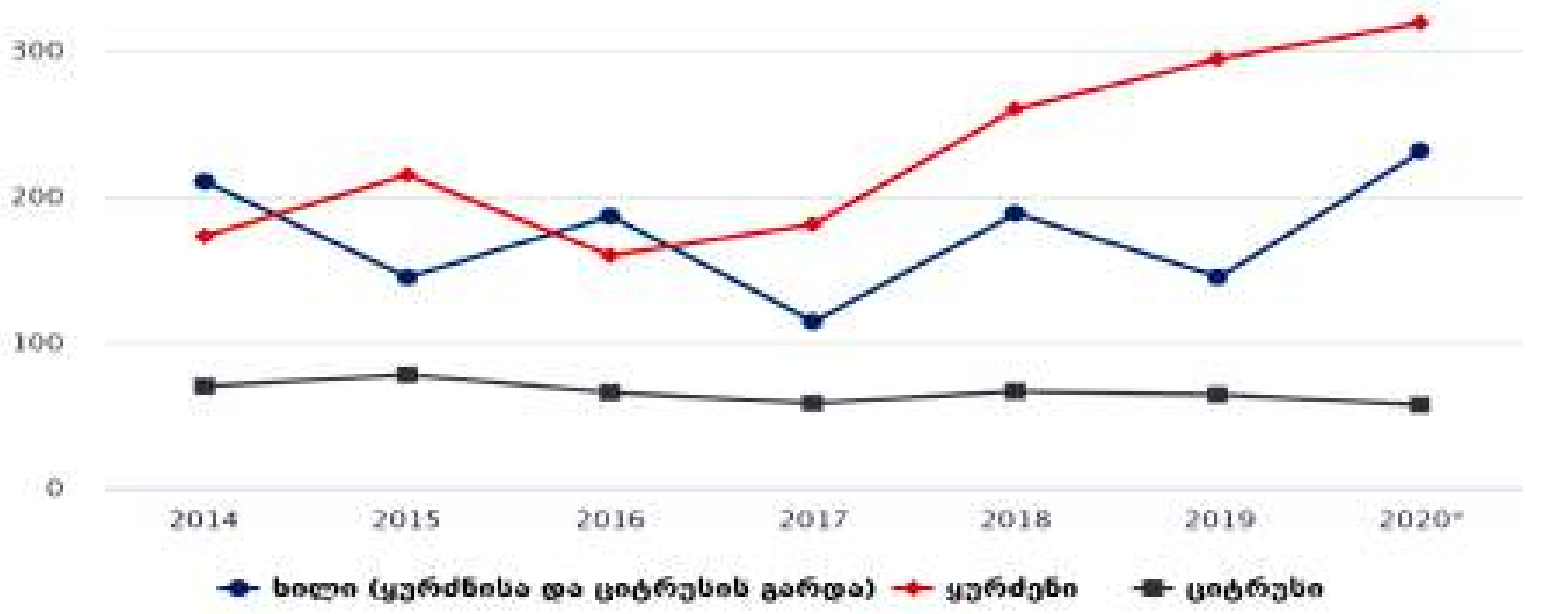

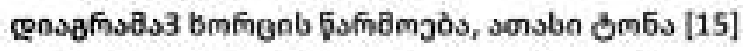

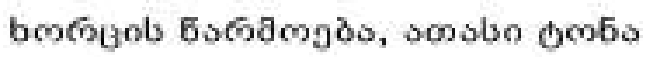

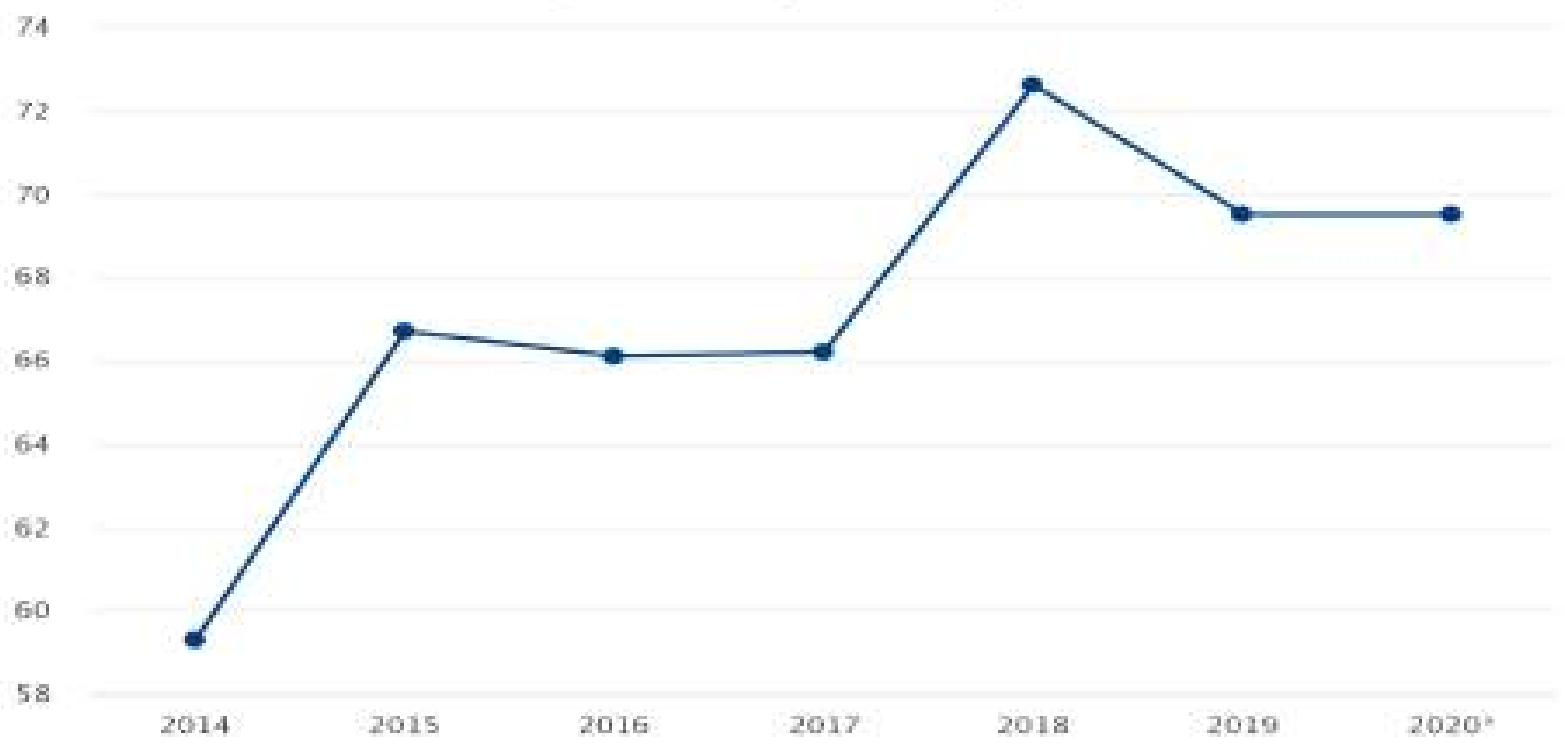

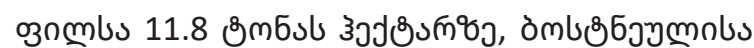

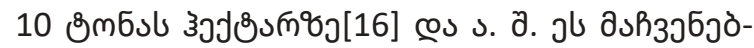

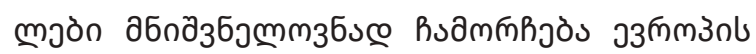

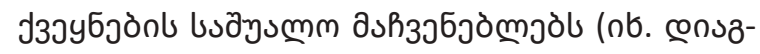
m̊à 4).

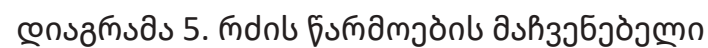

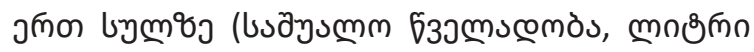

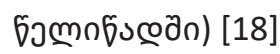

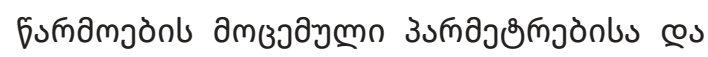

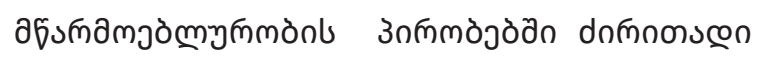




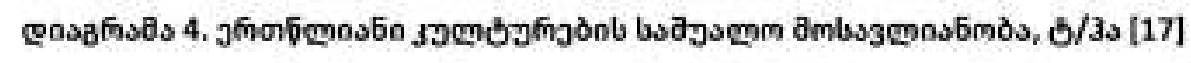

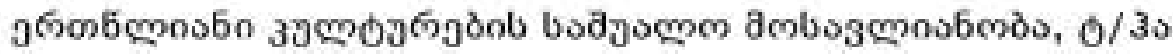

4

3

2

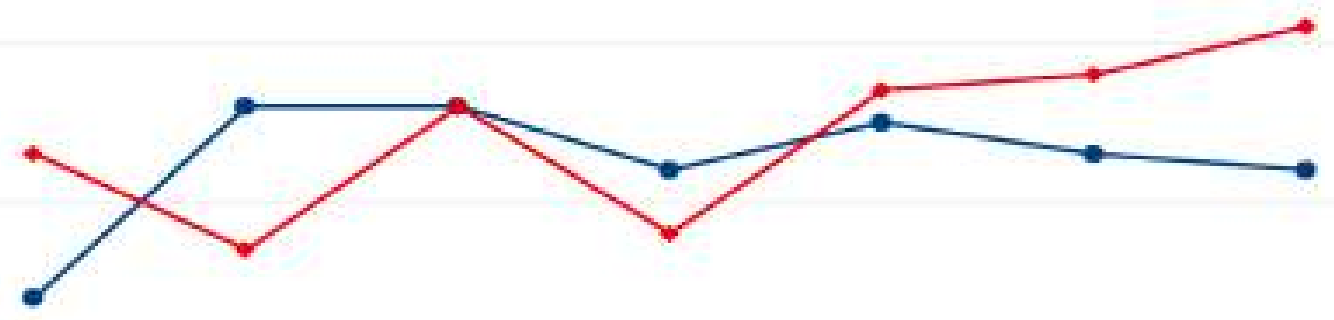

1.

0

$2014 \quad 2015 \quad 2017 \quad 2018 \quad 2019 \quad 2020^{*}$

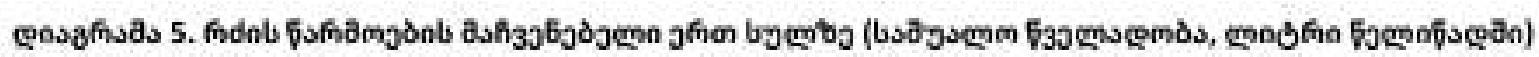
[18]

1560

1600

1460

1400

1350

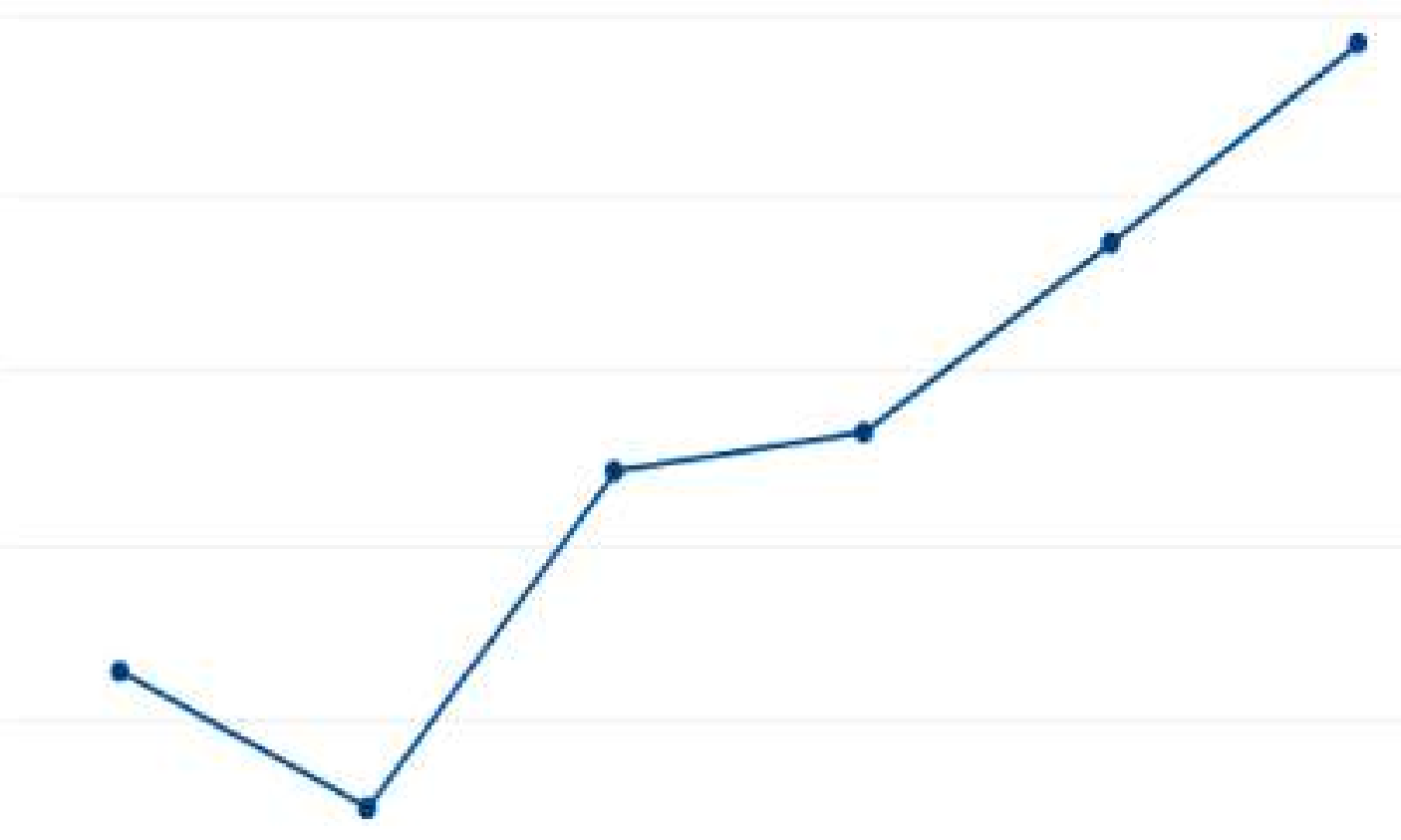

1300

\begin{tabular}{llllll}
\hline 2014 & 2015 & 2015 & 2017 & 2016 & 2019
\end{tabular}

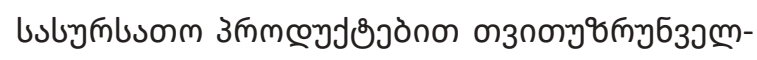

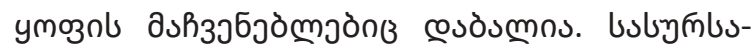

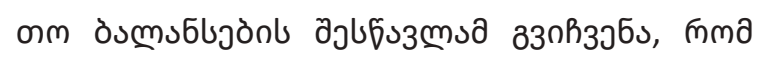

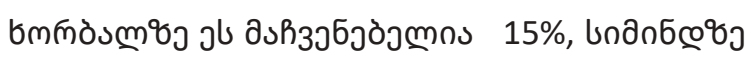

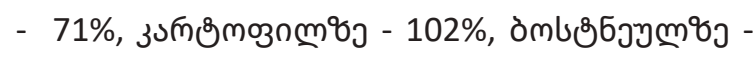

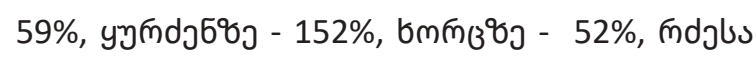




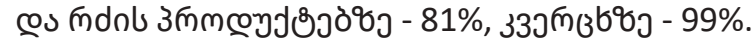

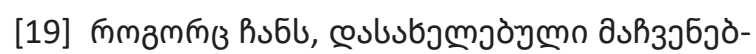

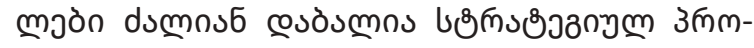

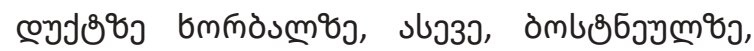

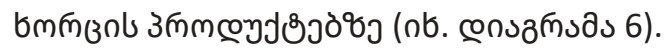

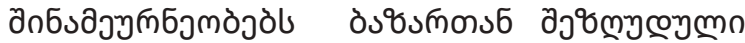

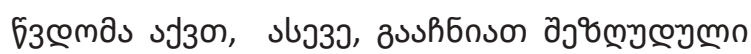

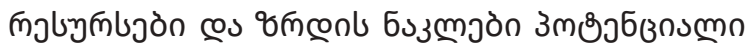
งป3on [25].

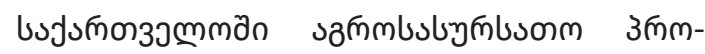

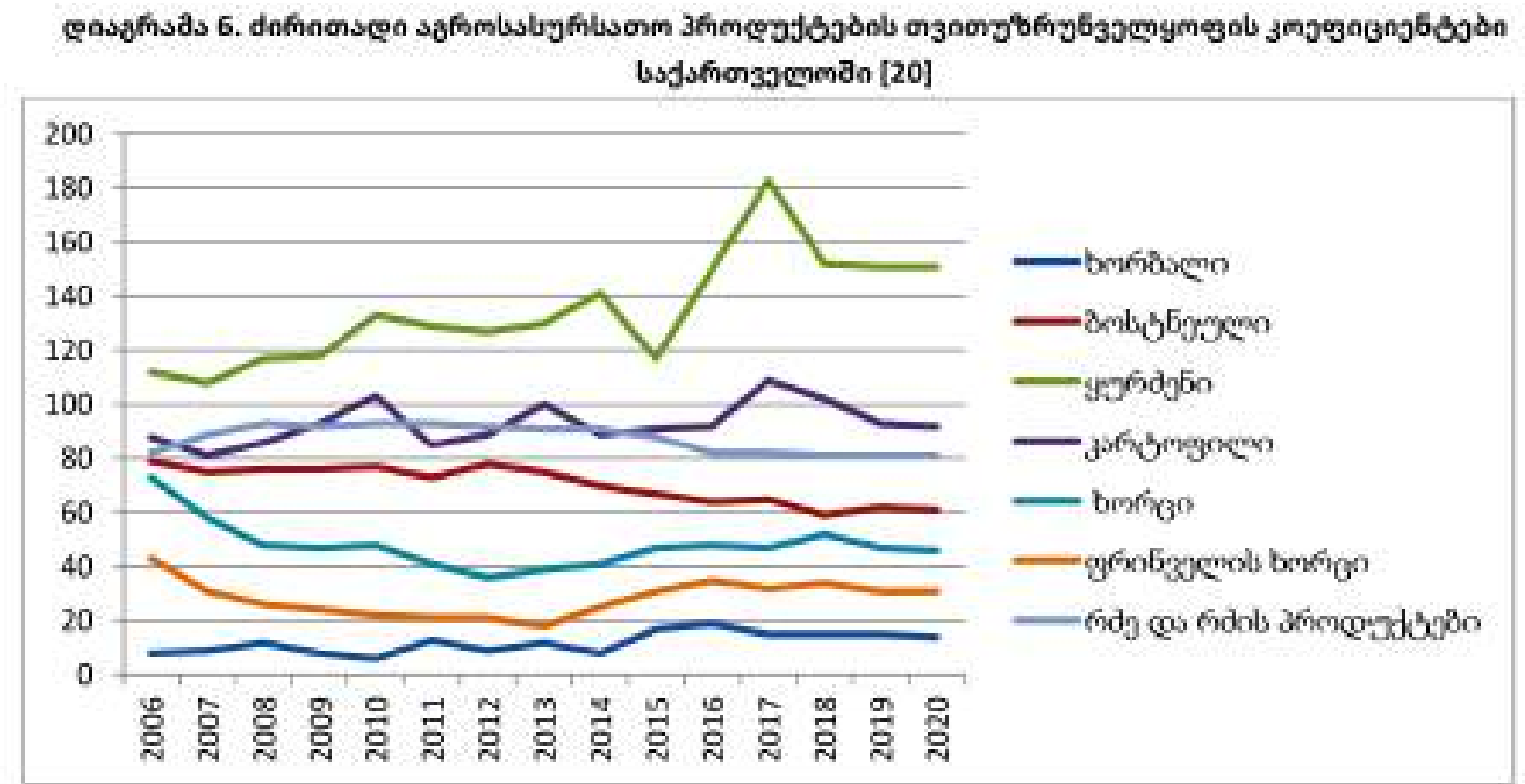

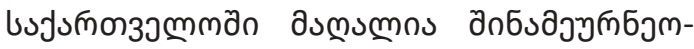

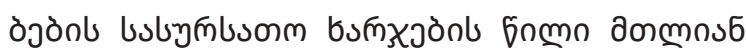

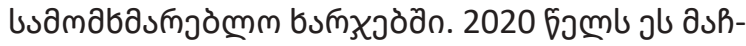

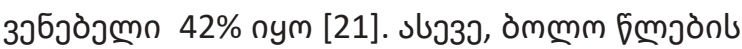

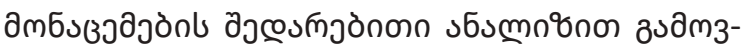

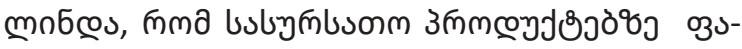

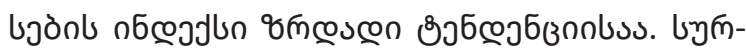

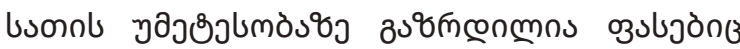
[22].

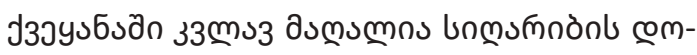

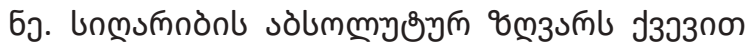

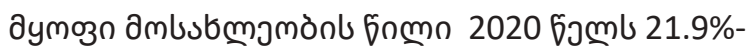
u nym [23].

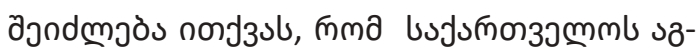

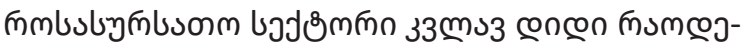

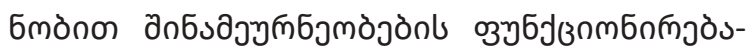

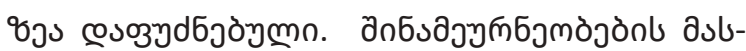

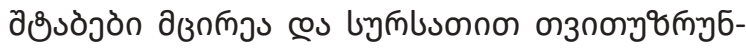

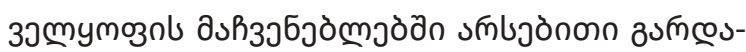

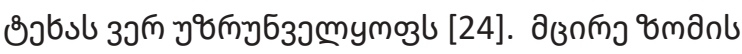

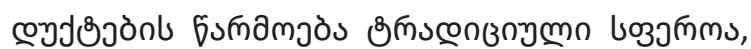

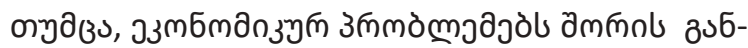

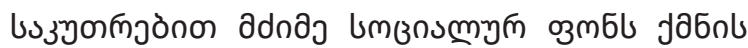

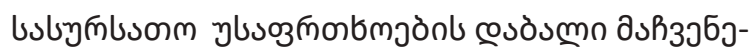

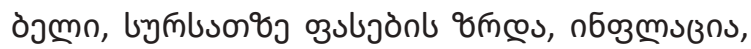

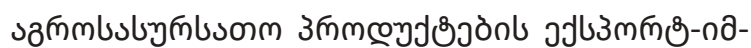

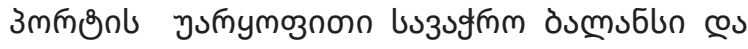
ub3 [26].

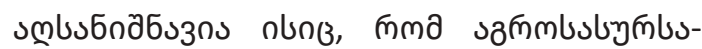

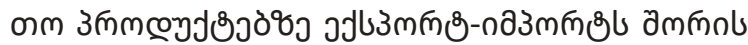

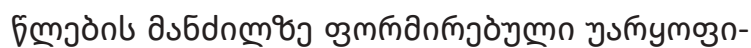

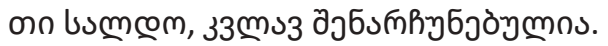

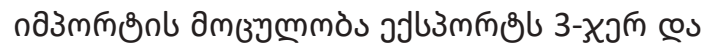

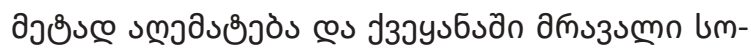

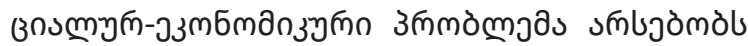
[27].

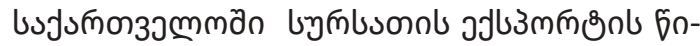

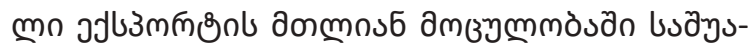

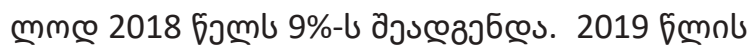

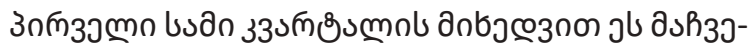

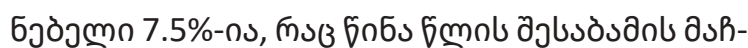




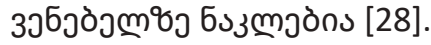

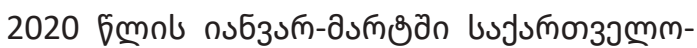

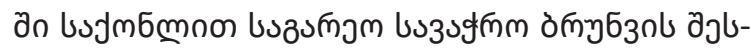

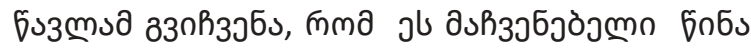

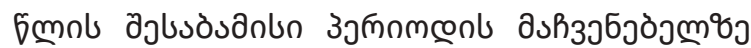

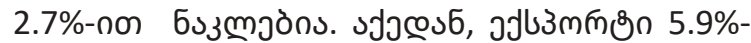

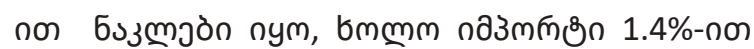

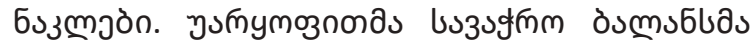

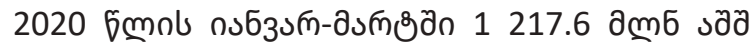

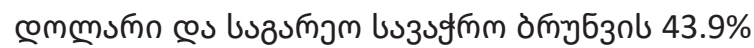

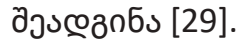

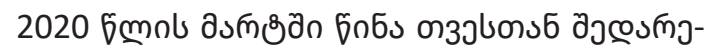

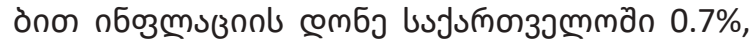

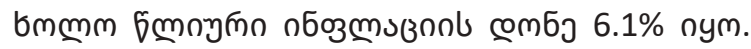

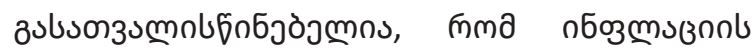

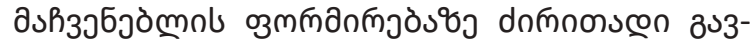

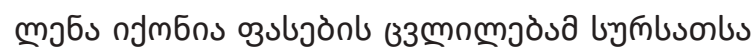

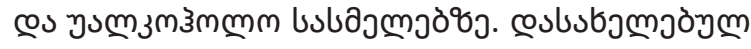

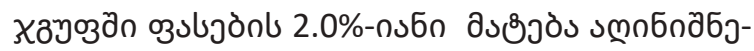

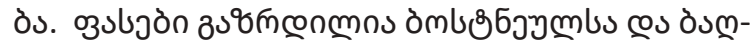

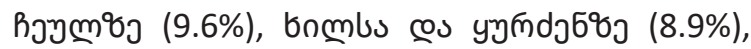

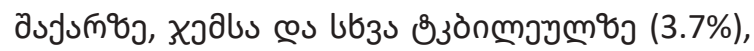

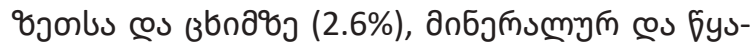

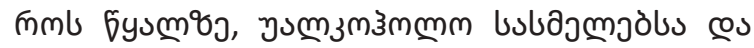

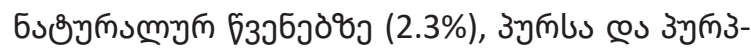

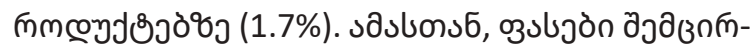

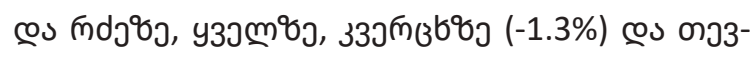
ชวทตุชว (-1.2\%) [30].

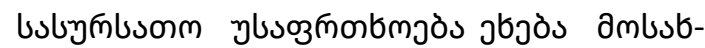

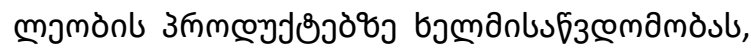

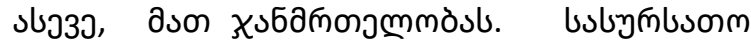

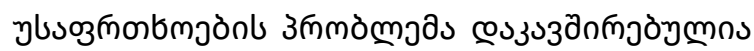

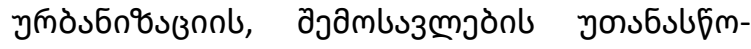

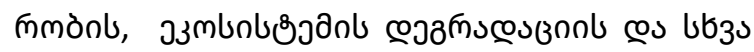

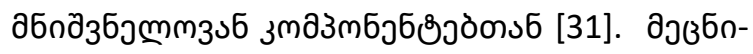

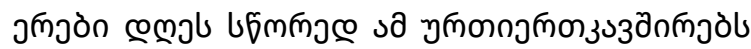

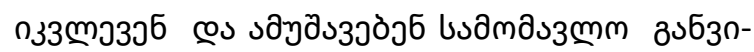

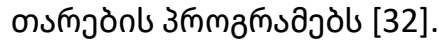

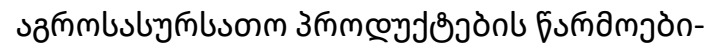

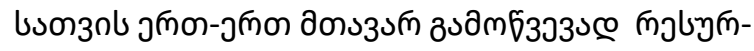

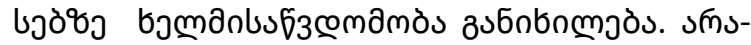

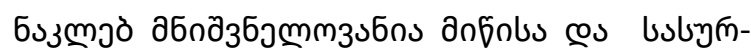

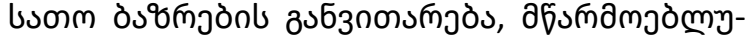

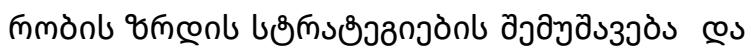

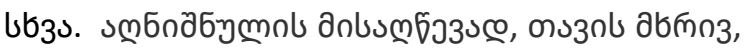

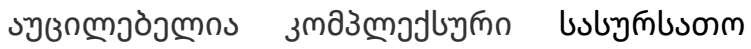

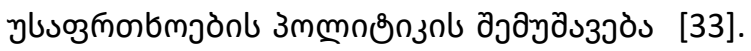

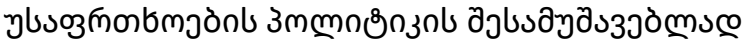

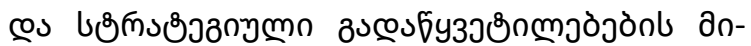

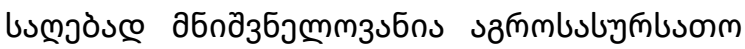

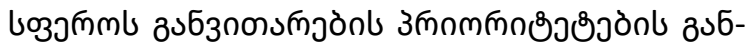

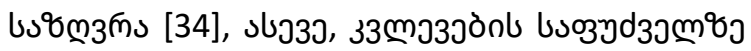

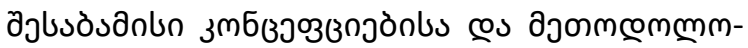

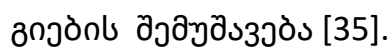

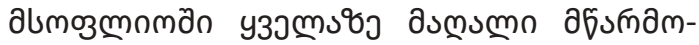

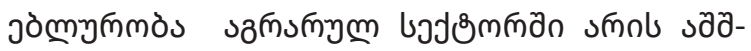

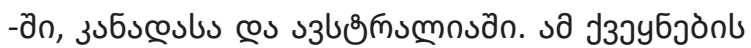

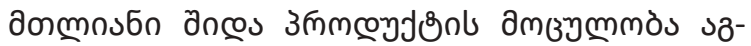

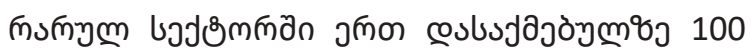

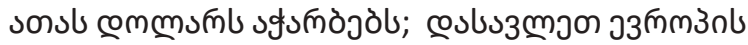

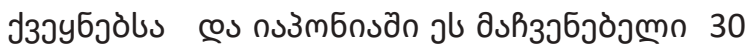

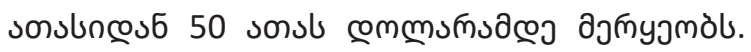

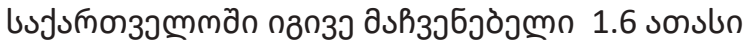

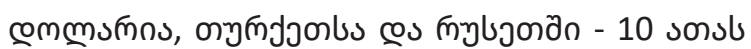

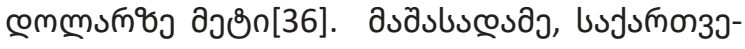

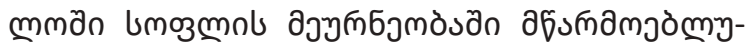

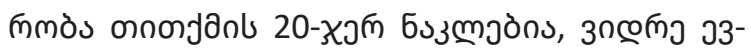

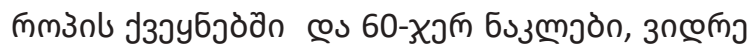

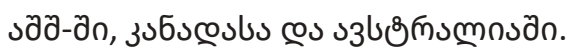

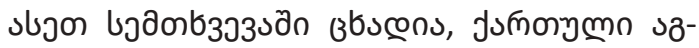

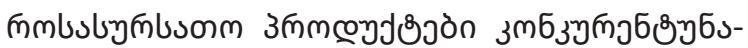

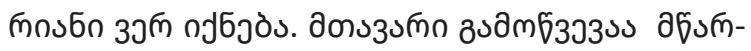

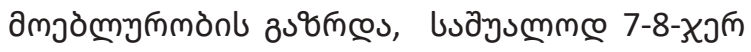

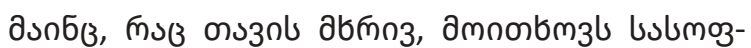

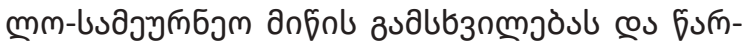

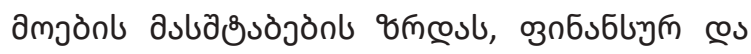

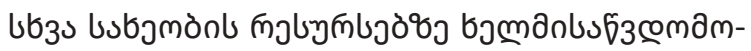

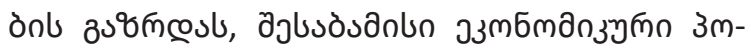
mกఠిกзn

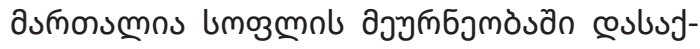

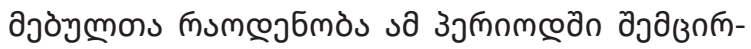

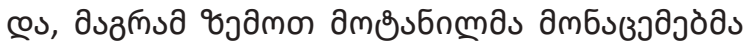

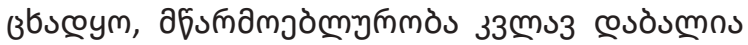

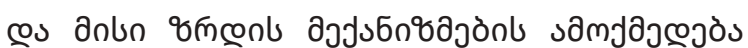




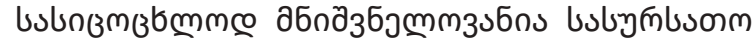

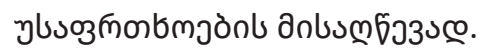

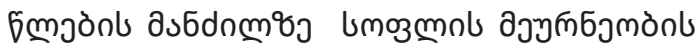

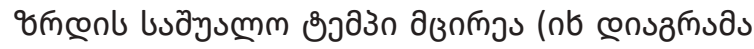
7).

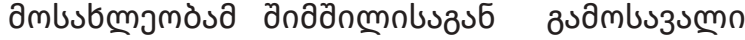

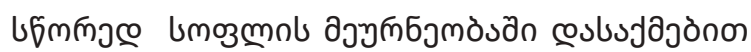

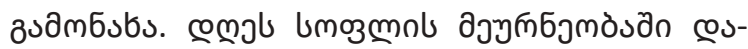

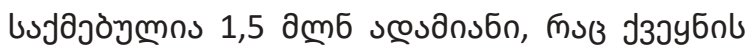

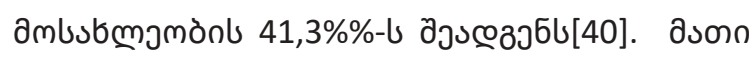

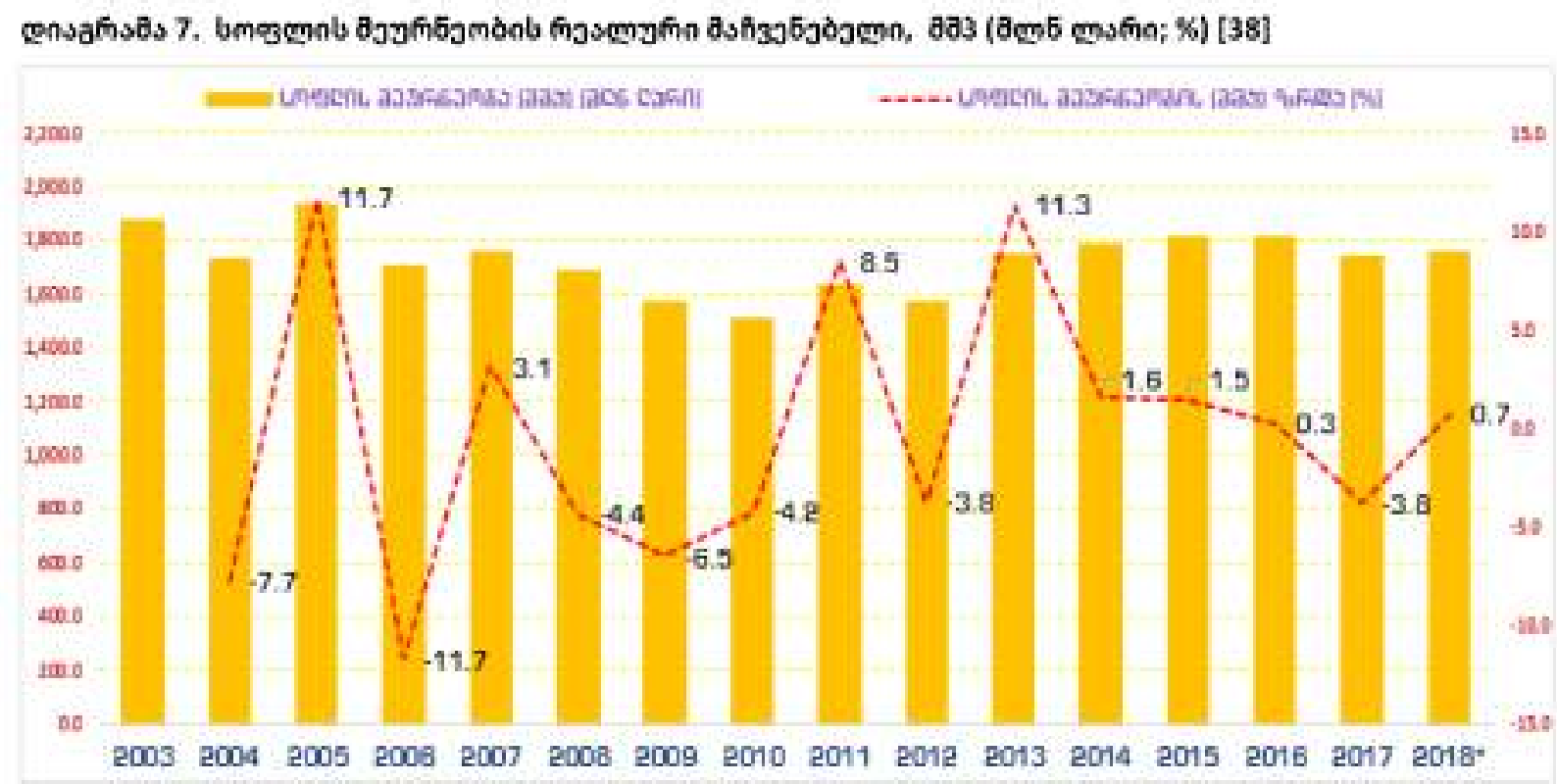

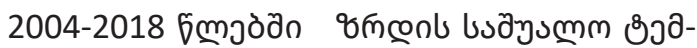

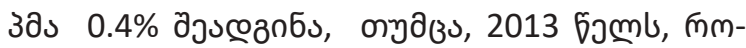

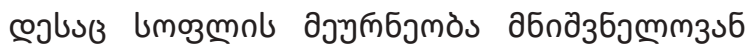

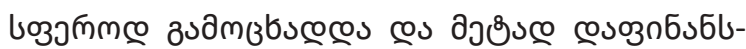

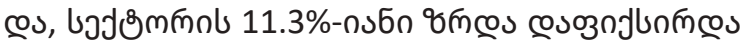

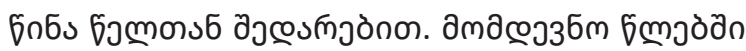

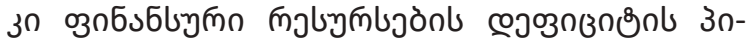

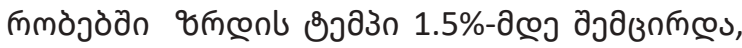

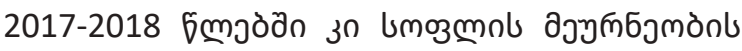

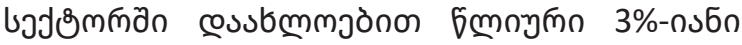

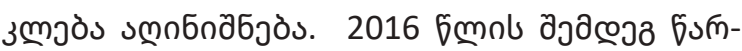

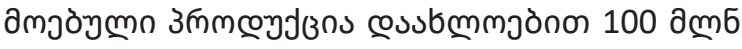

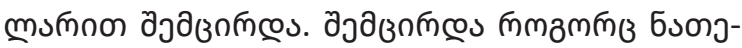

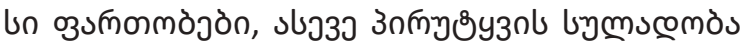
[39].

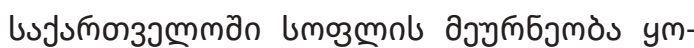

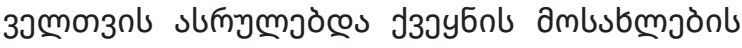

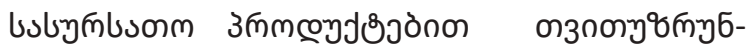

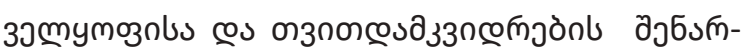

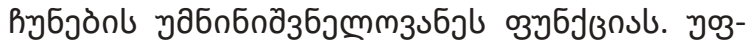

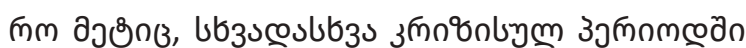

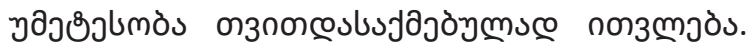

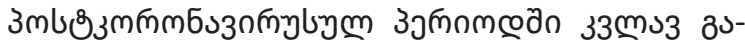

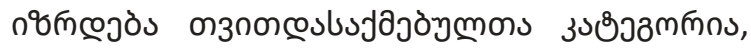

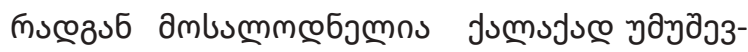

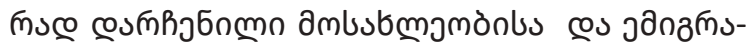

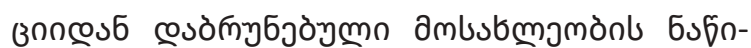

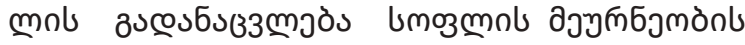

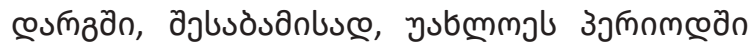

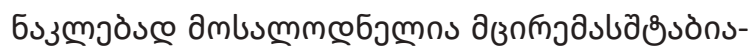
б

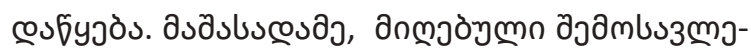

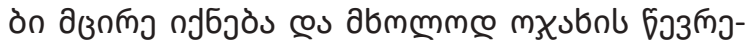

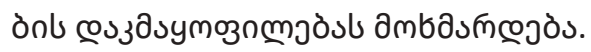

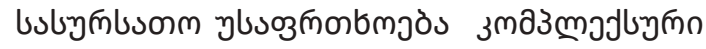

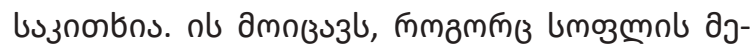

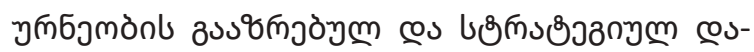

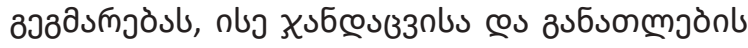

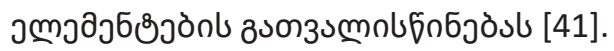

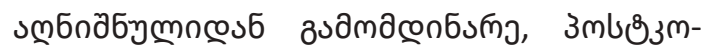

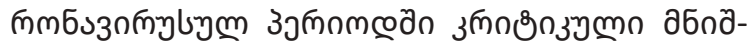

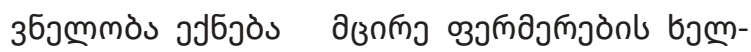




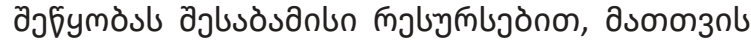

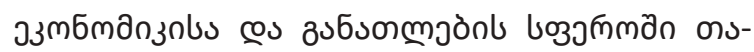

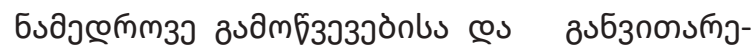

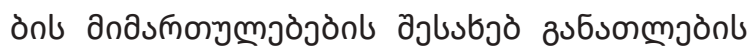

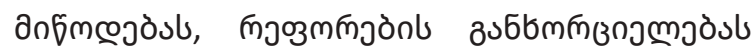

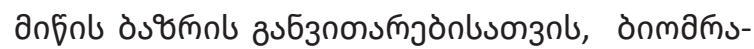

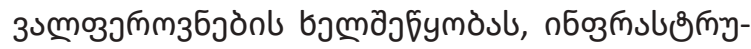

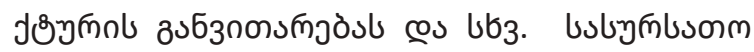

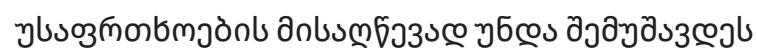

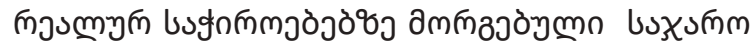

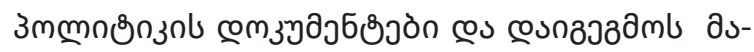

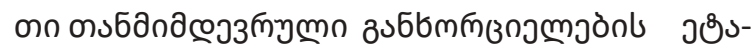
Зวอ̀ก.

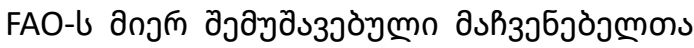

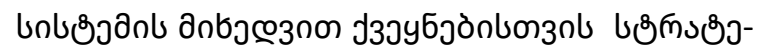

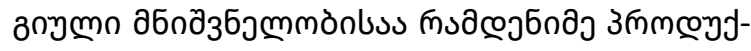

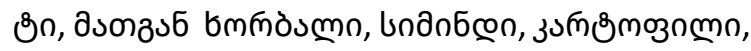

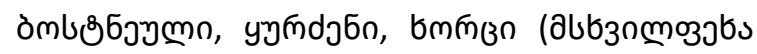

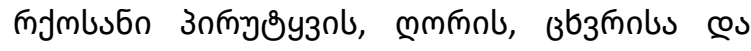

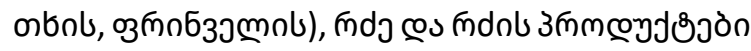

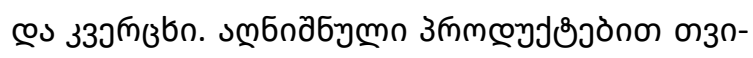

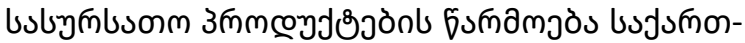

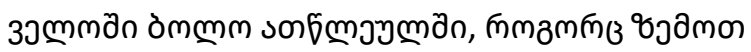

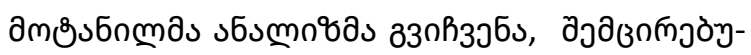

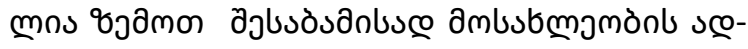

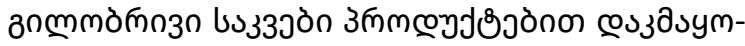

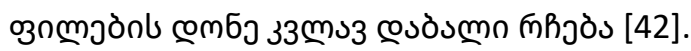

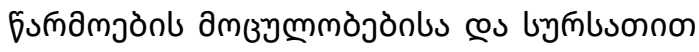

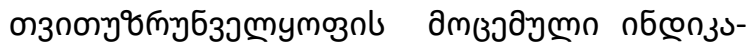

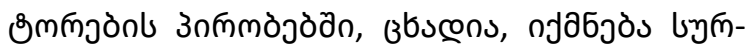

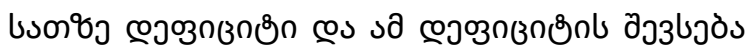

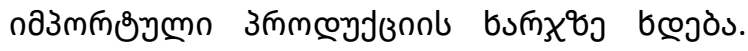

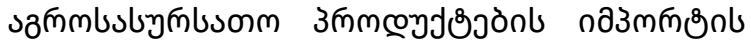

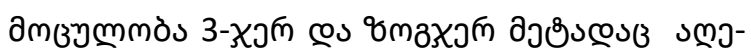

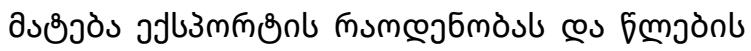

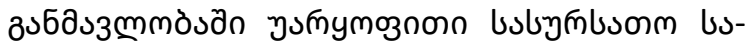

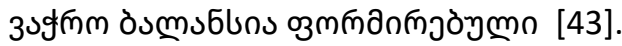

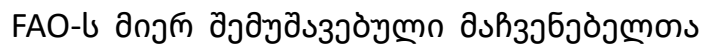

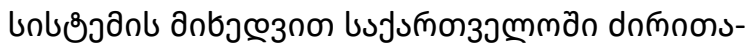

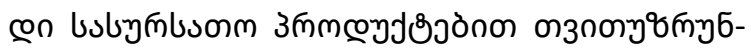

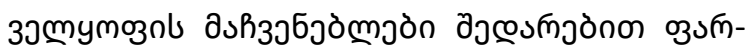

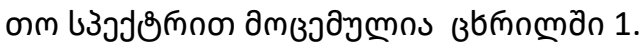

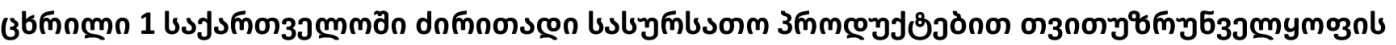

\begin{tabular}{|c|c|c|}
\hline 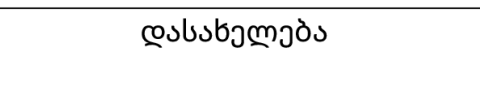 & 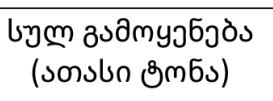 & 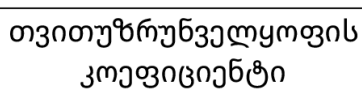 \\
\hline bmற்̉ेumo & 796 & $15 \%$ \\
\hline unanбตn & 402 & $71 \%$ \\
\hline 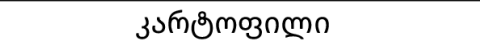 & 286 & $102 \%$ \\
\hline 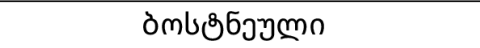 & 286 & $59 \%$ \\
\hline yymdjбn & 427 & $152 \%$ \\
\hline bmmुo & 157,7 & $52 \%$ \\
\hline 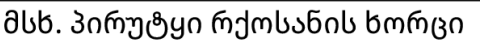 & 30,5 & $77 \%$ \\
\hline мmmol bmm̄̋n & 42,1 & $45 \%$ \\
\hline 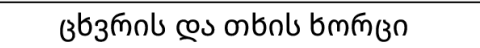 & 9,9 & $295 \%$ \\
\hline 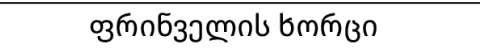 & 74,8 & $34 \%$ \\
\hline 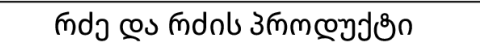 & 704 & $81 \%$ \\
\hline з3эmъ6n & 678 & $99 \%$ \\
\hline
\end{tabular}

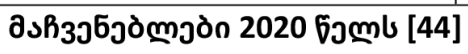

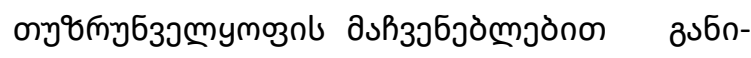

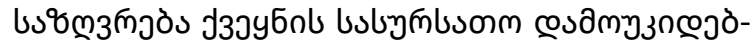

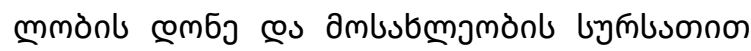

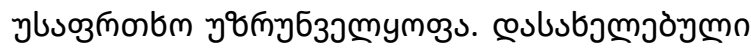

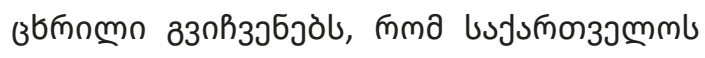

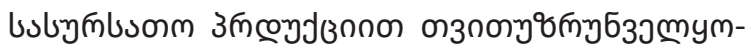

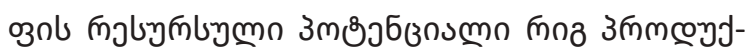

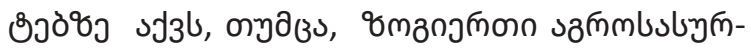




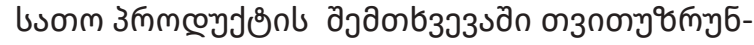

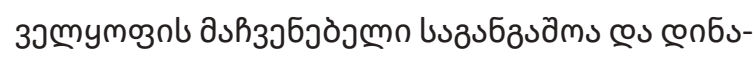

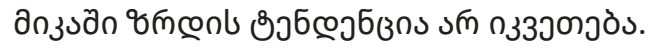

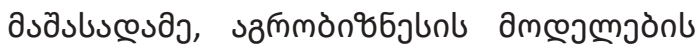

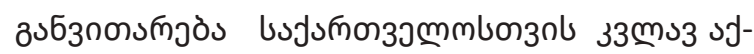

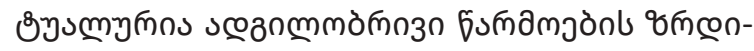
bsonzol [45].

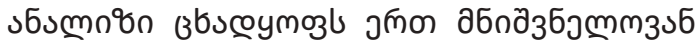

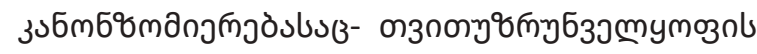

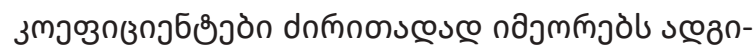

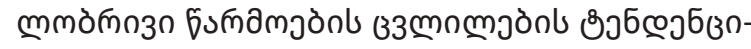

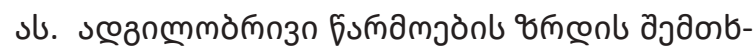

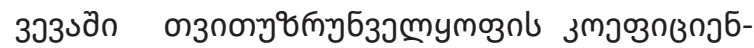

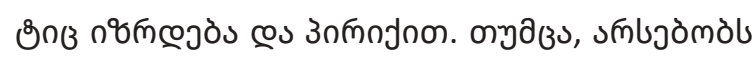

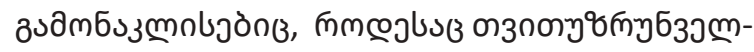

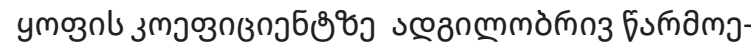

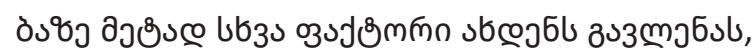

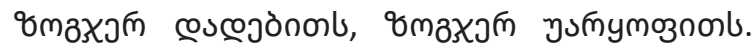

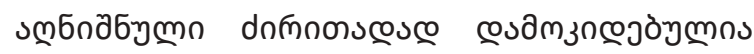

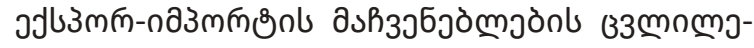

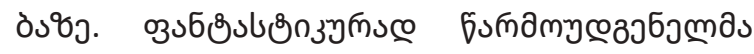

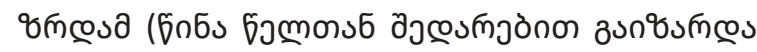

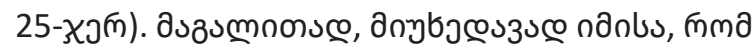

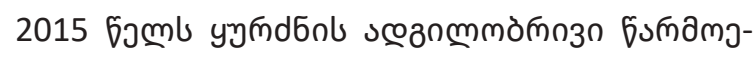

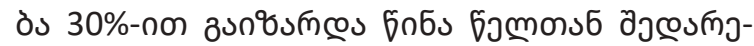

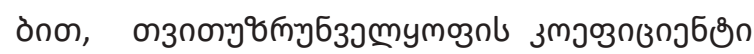

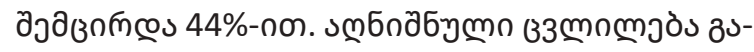

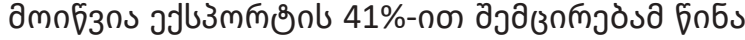

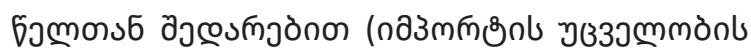

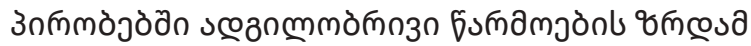

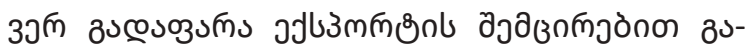

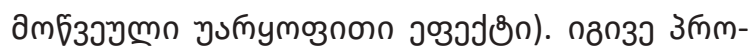

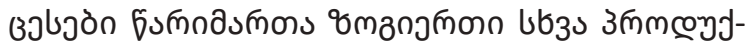

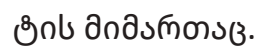

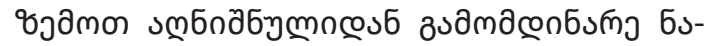

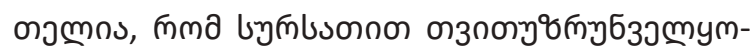

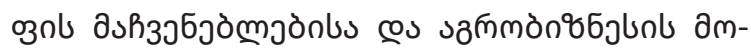

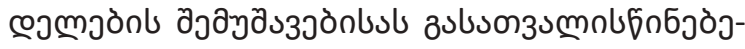

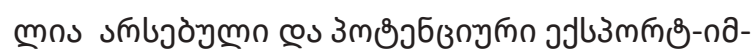

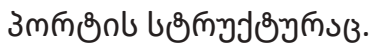

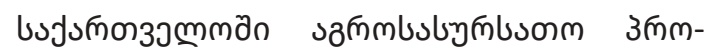

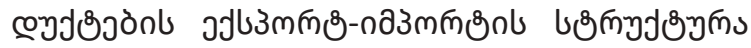

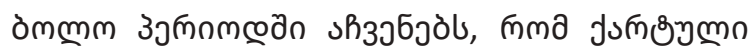

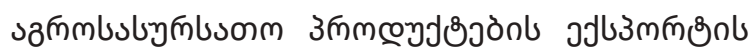

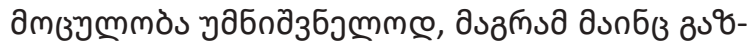

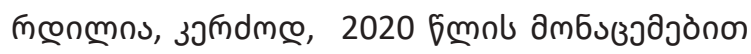

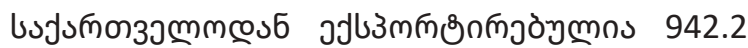

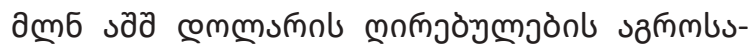

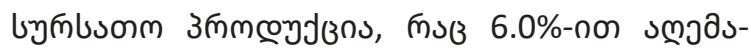

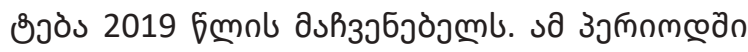

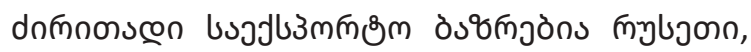

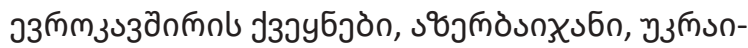

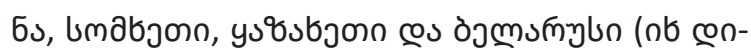
งวต்งวง 8).

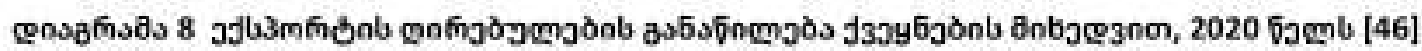

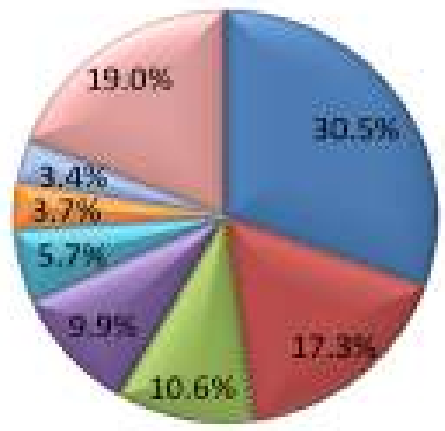

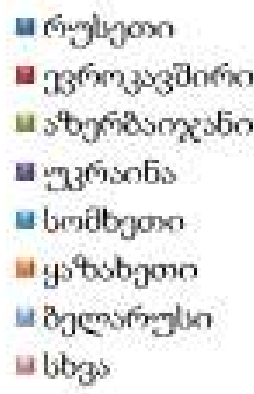




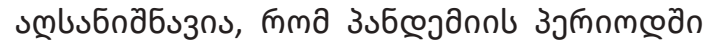

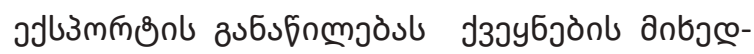

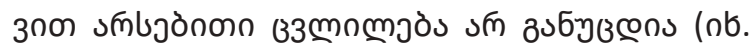

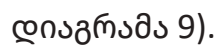

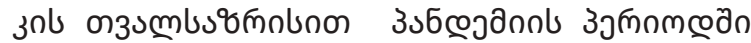

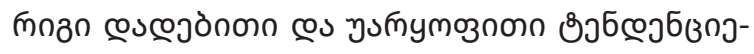

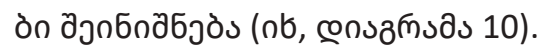

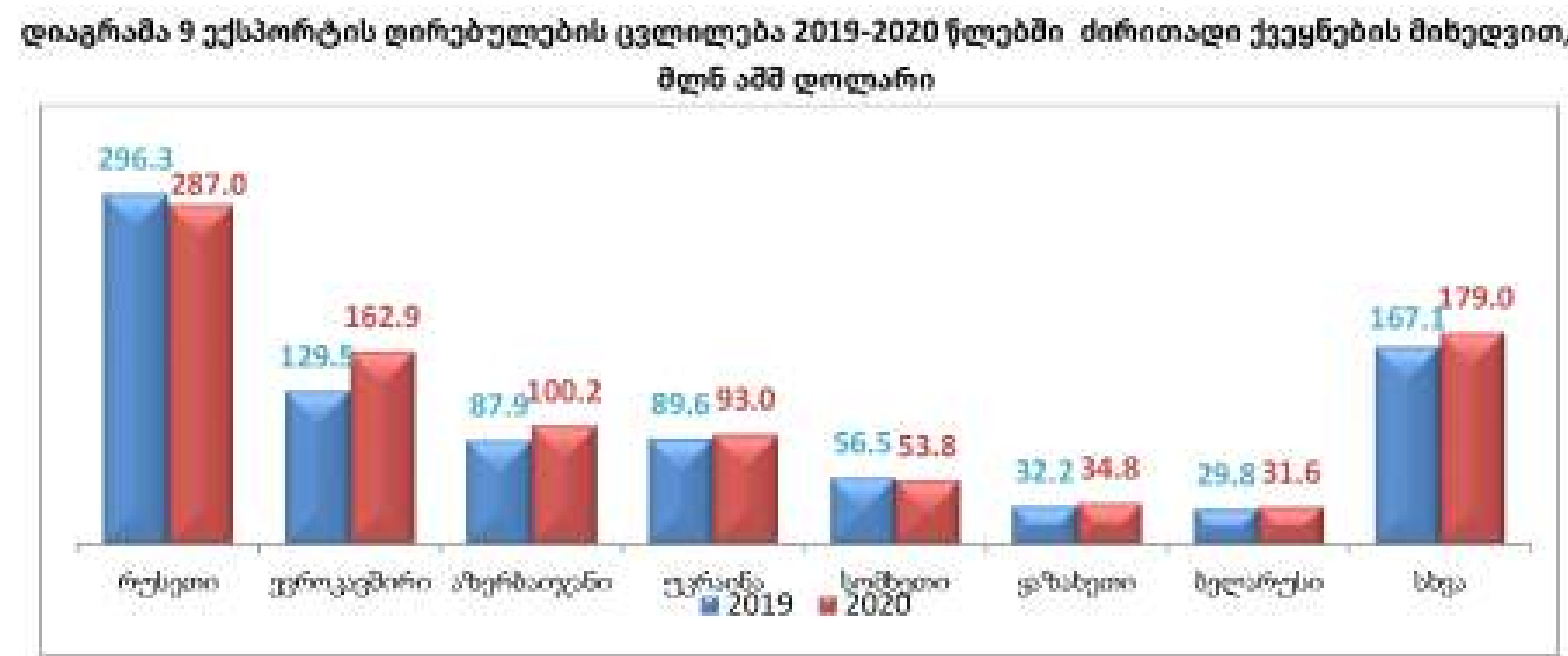

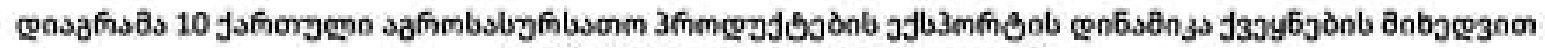

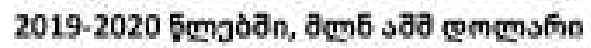

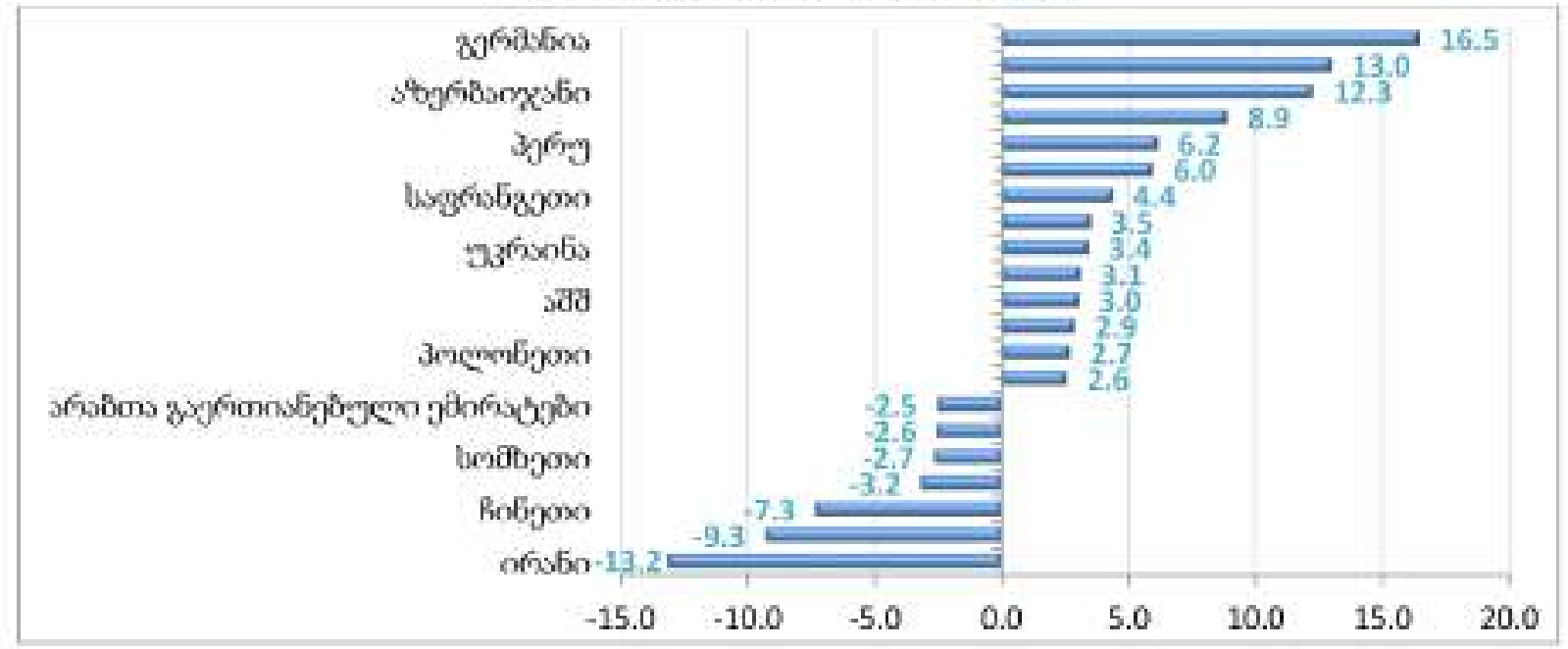

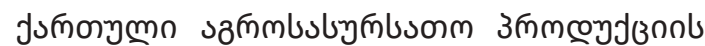

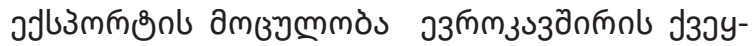

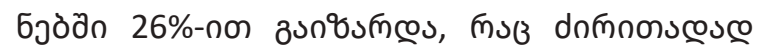

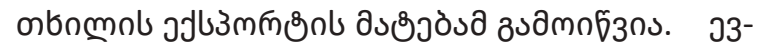

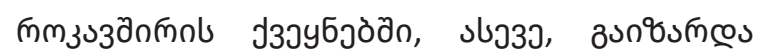

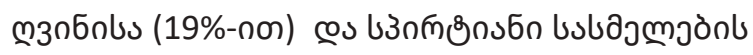

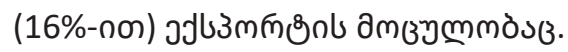

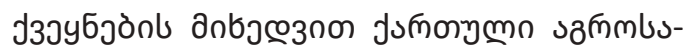

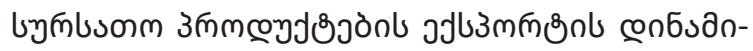

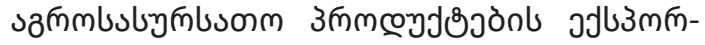

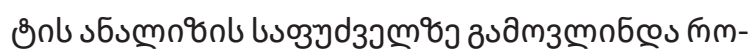

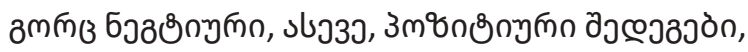

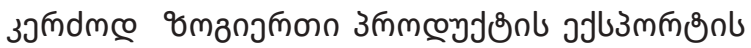

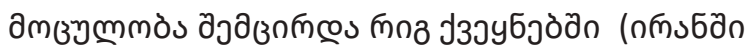

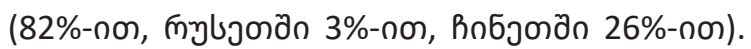

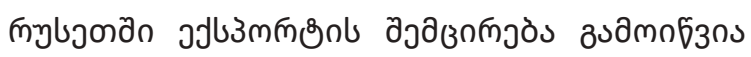

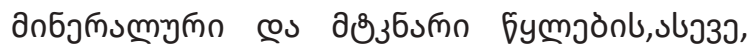

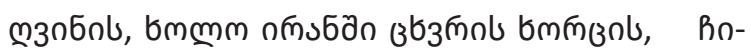




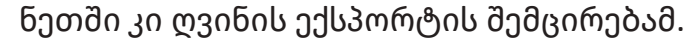

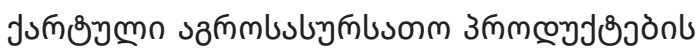

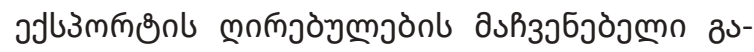

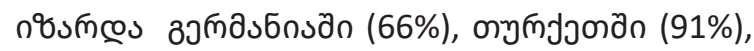

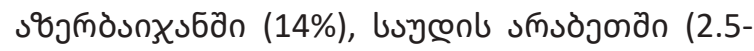

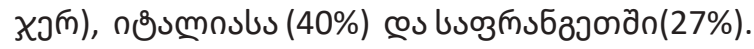

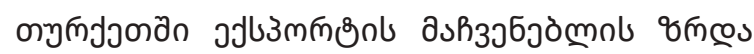

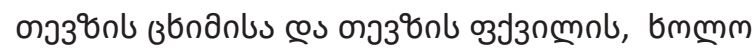

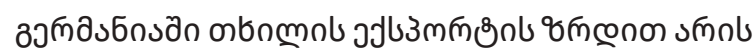

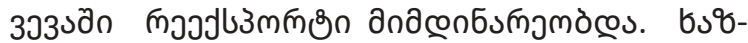

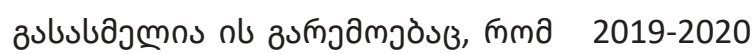

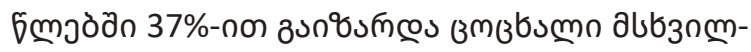

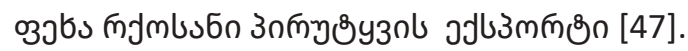

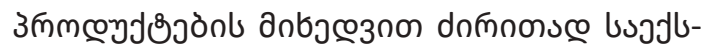

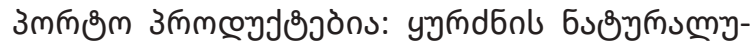

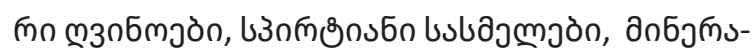

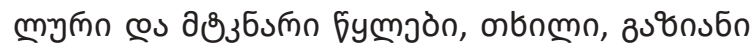

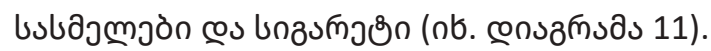

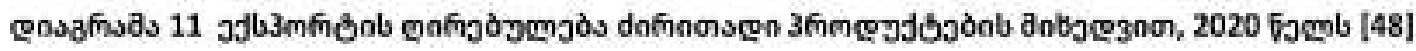

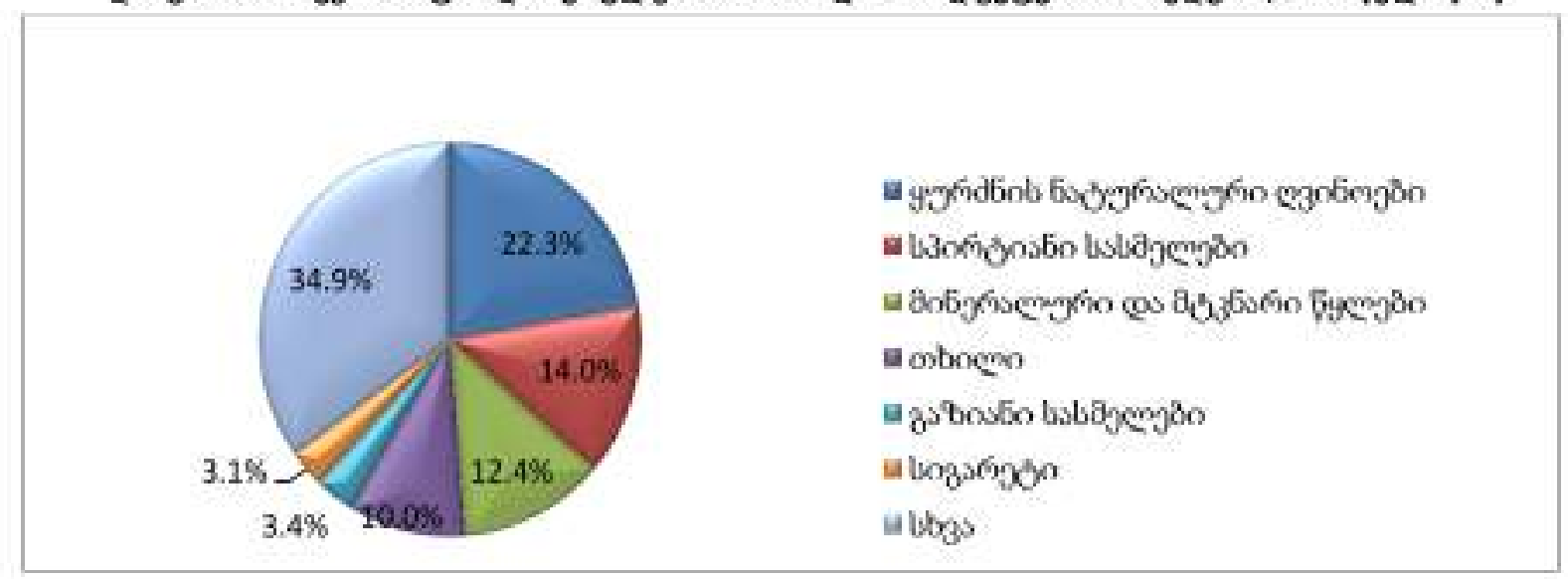

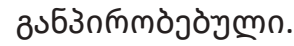

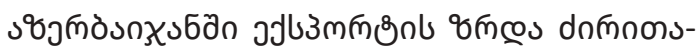

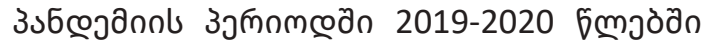

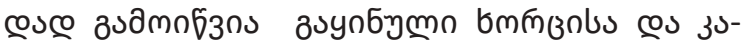

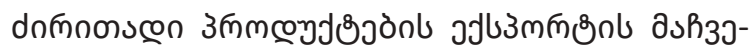

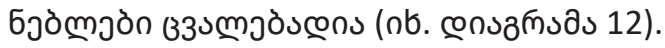

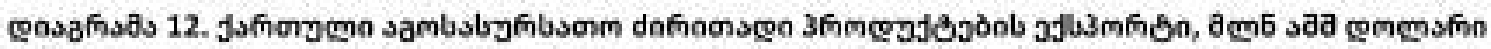

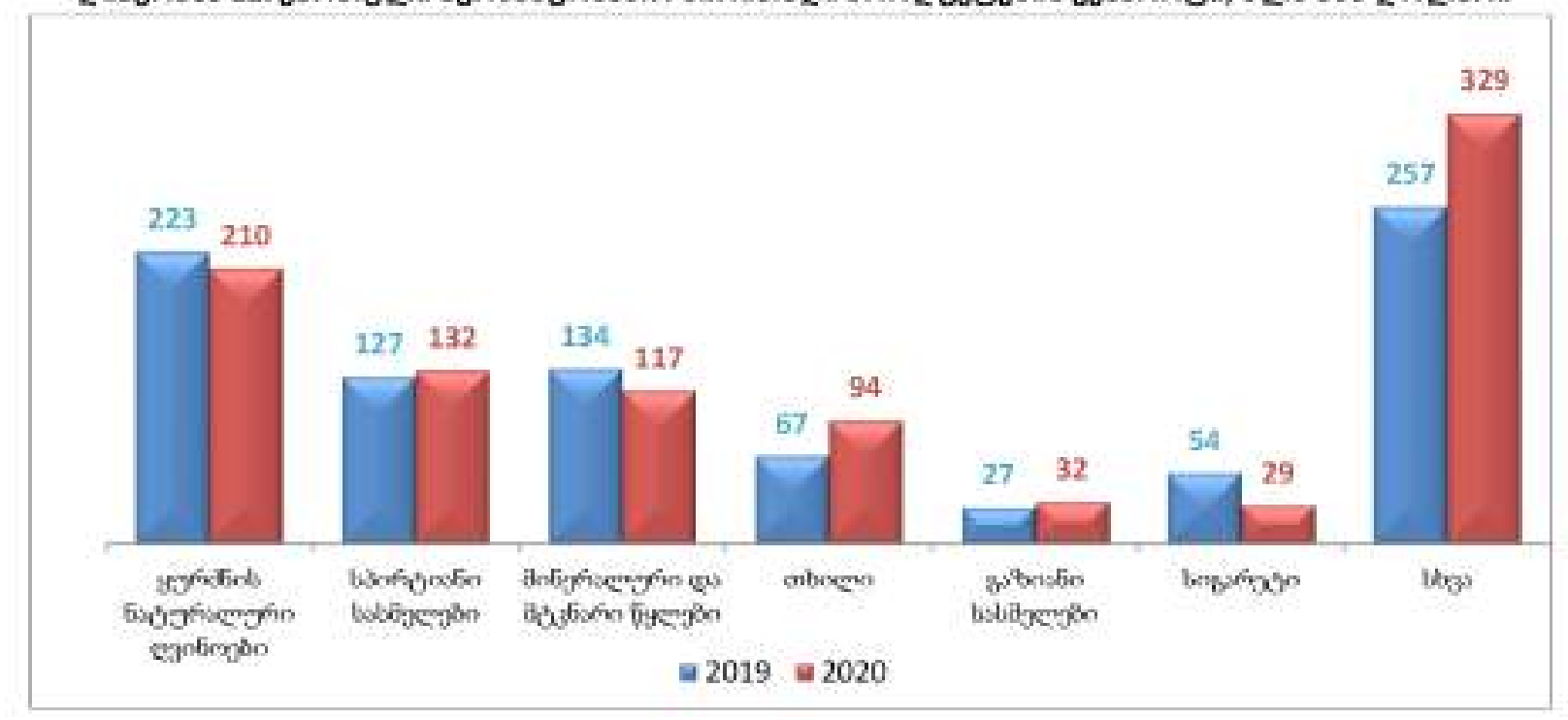

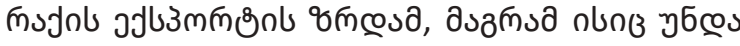

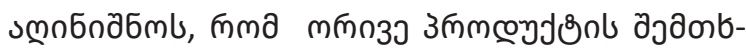

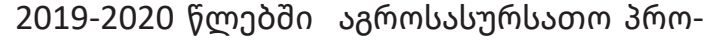

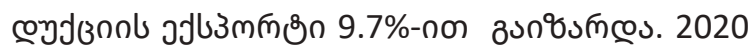




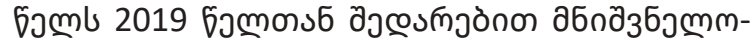

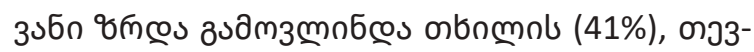

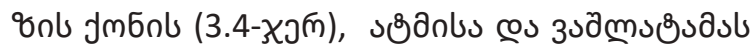

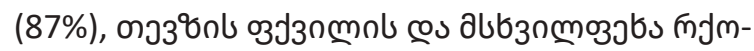

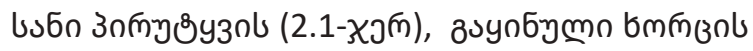

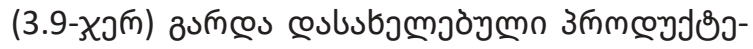

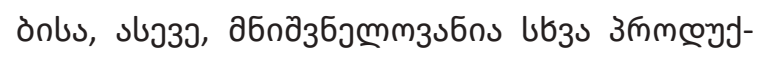

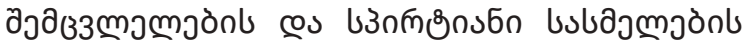

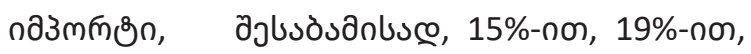
51\%-noms @อ 25\%-non.

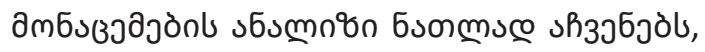

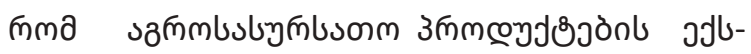

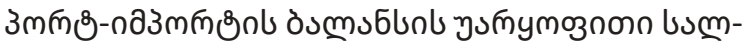

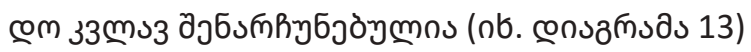

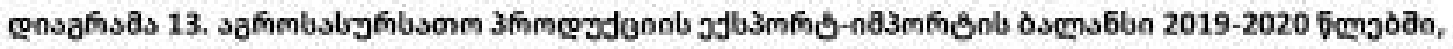
apm5 saa pmensfino [49]

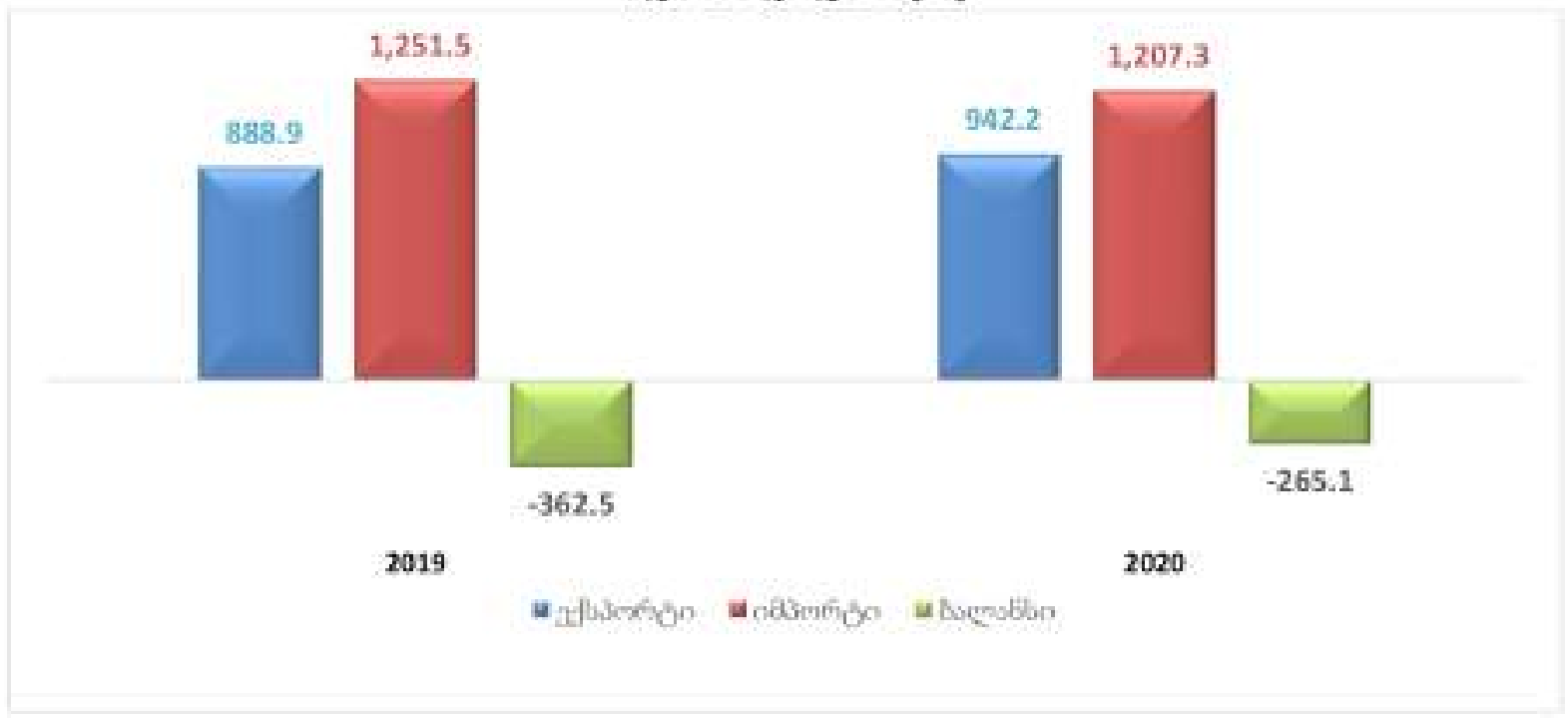

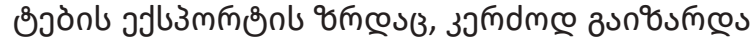

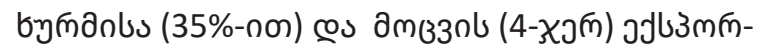
ఠిก.

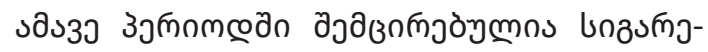

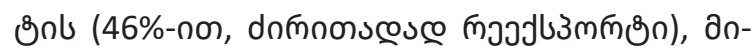

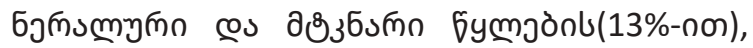

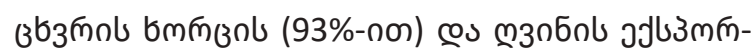
ठిపेก (6\%-no)).

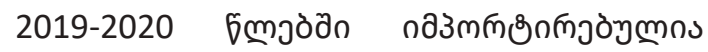

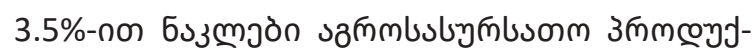

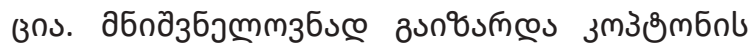

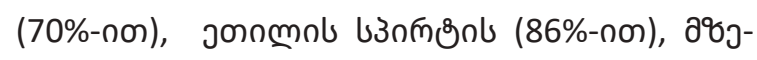

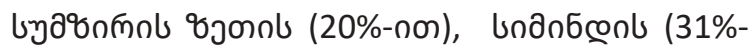

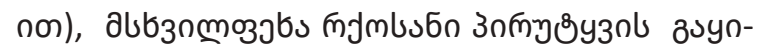

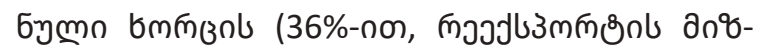

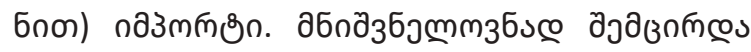

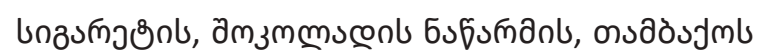

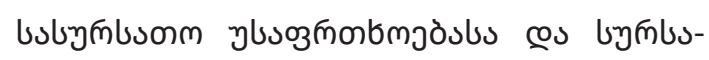

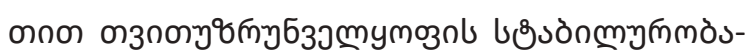

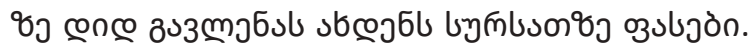

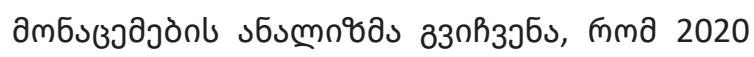
6mol s3mnmãn 2019 6mol dolusòsanb 3jmn-

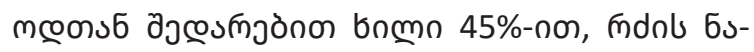

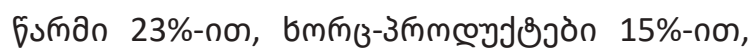

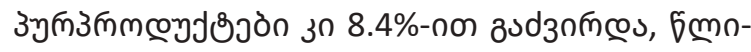

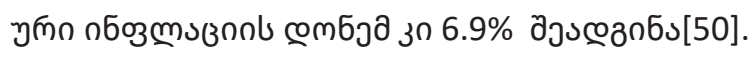

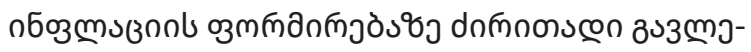

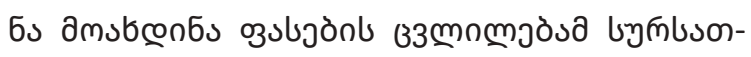

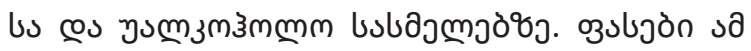

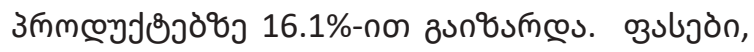

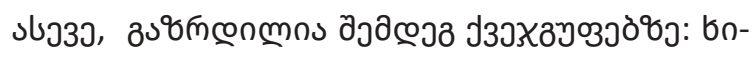

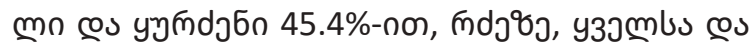

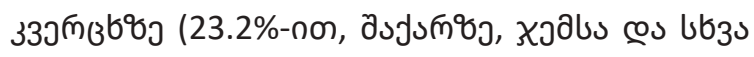

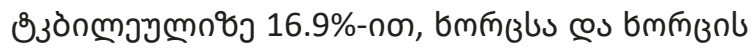




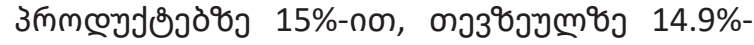

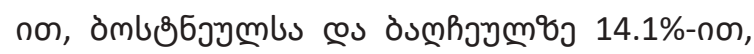

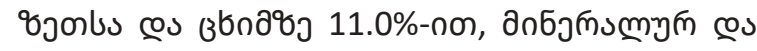

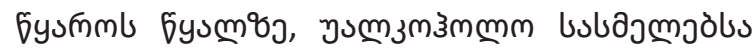

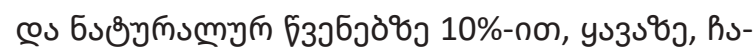

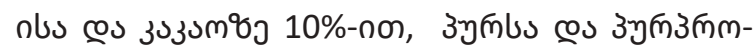

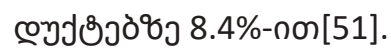

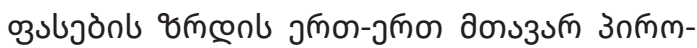

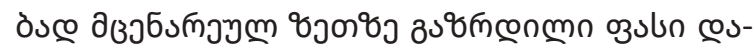

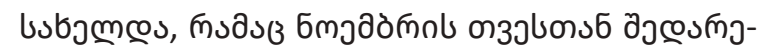

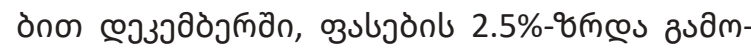

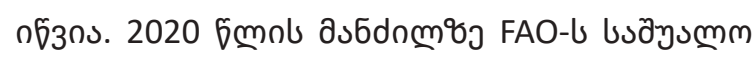

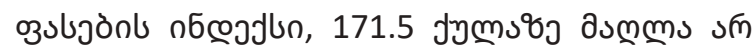

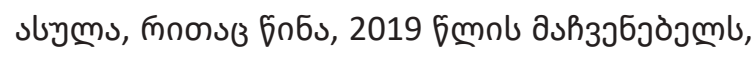

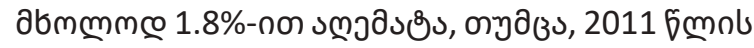

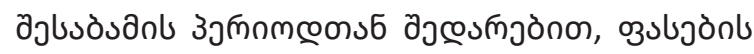

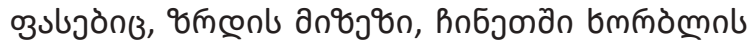

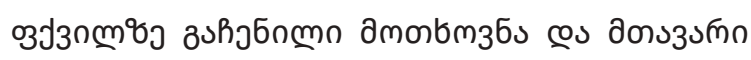

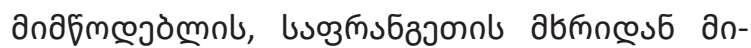
бмৎృ

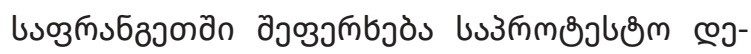

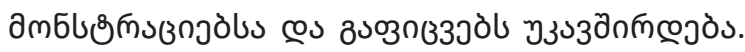

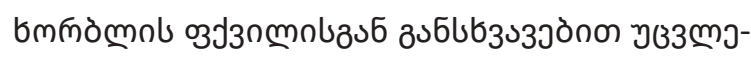

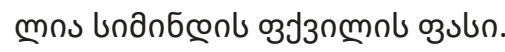

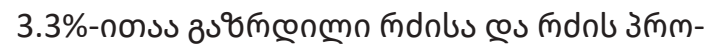

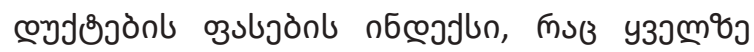

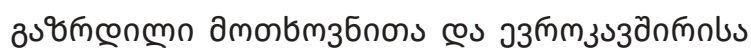

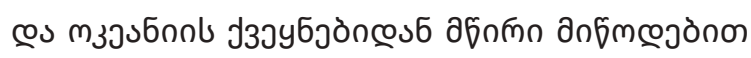
sก৮ட6วd̀s[52].

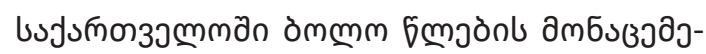

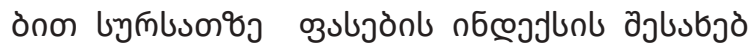

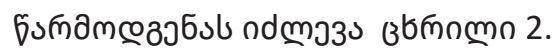

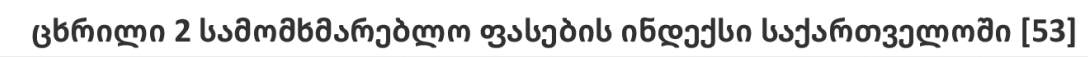

\begin{tabular}{|c|c|c|c|c|c|c|c|c|c|}
\hline & 2012 & 2013 & 2014 & 2015 & 2016 & 2017 & 2018 & 2019 & 2020 \\
\hline 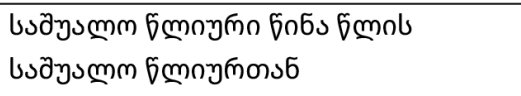 & 99.1 & 99.5 & 103.1 & 104 & 102.1 & 106 & 102.6 & 104.9 & 105.2 \\
\hline 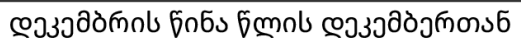 & 98.1 & 102.4 & 102 & 104.9 & 101.8 & 106.7 & 101.5 & 107 & 102.4 \\
\hline
\end{tabular}

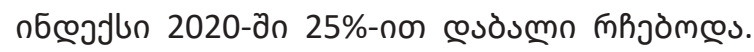

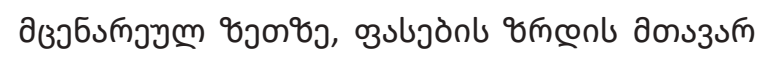

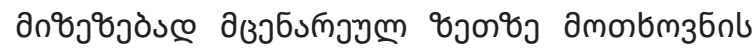

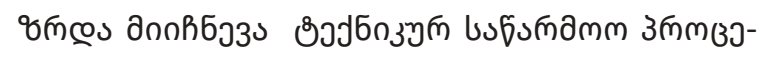

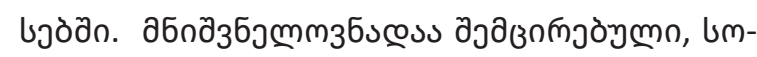

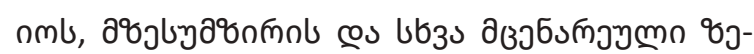

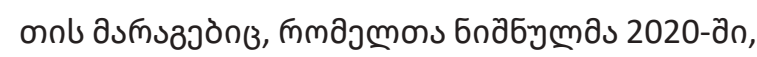

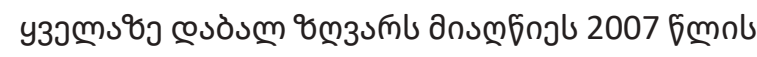

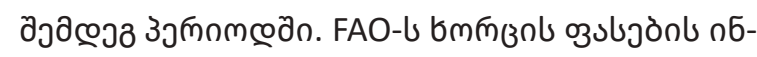

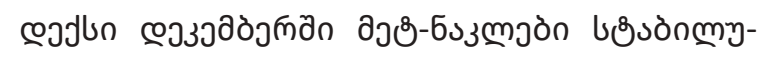

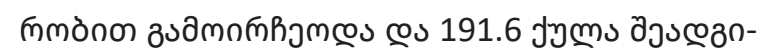

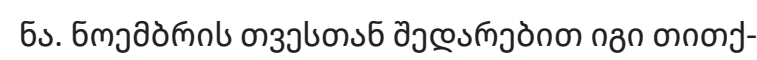

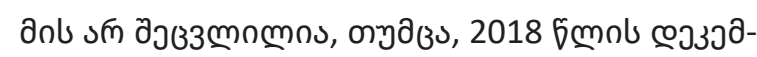

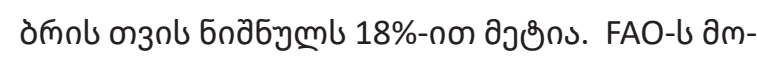

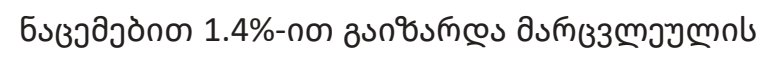

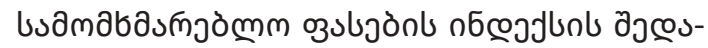

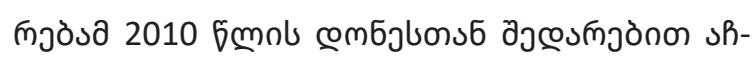

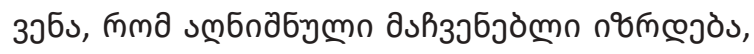

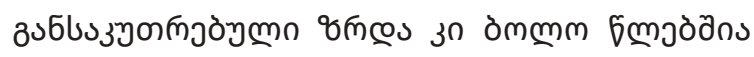

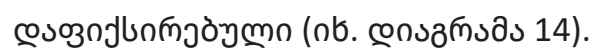

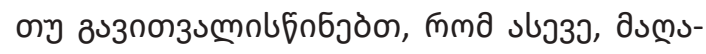

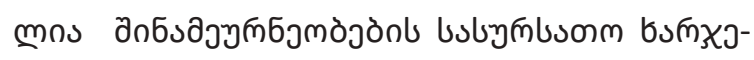

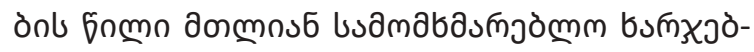

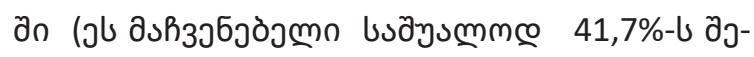

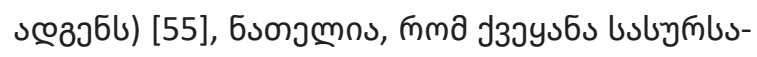

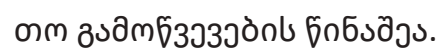

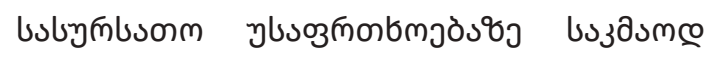

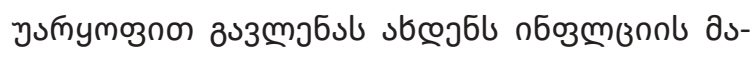

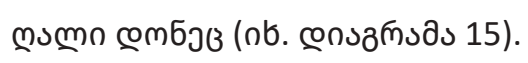

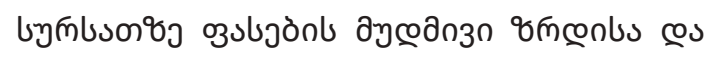




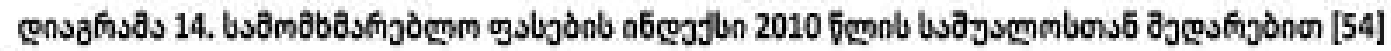

150

140

130

120

100

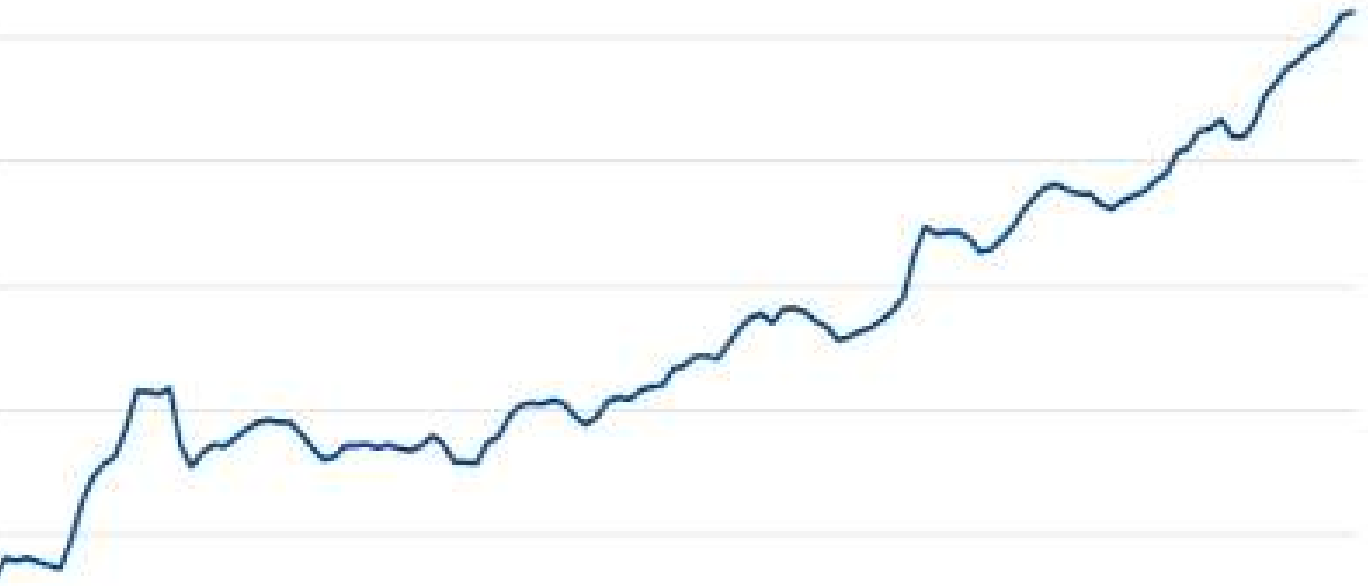

90

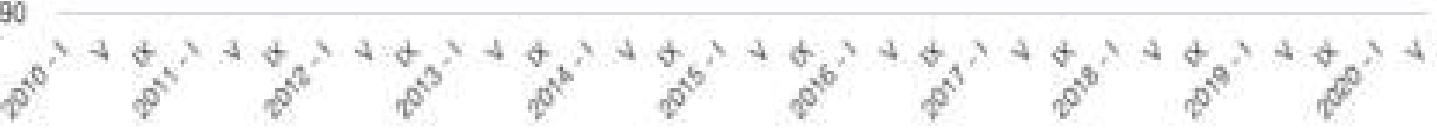

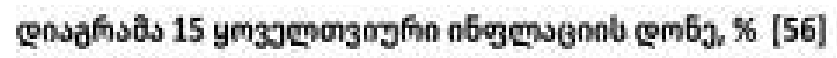

4

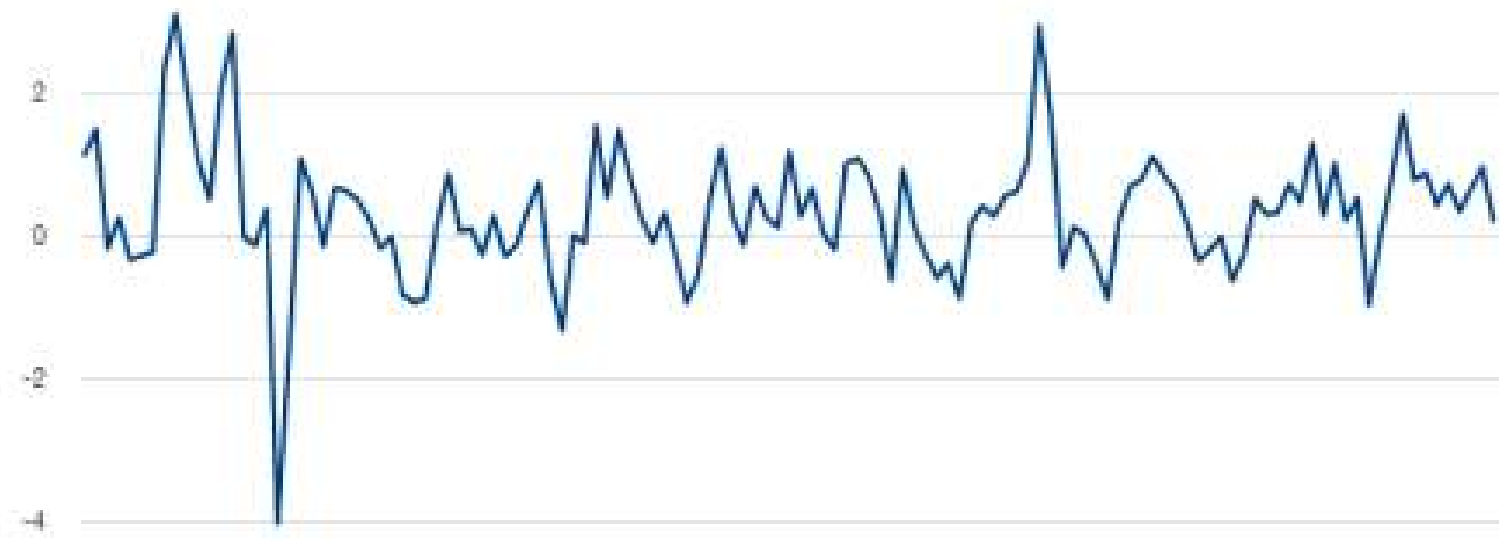

$-6$

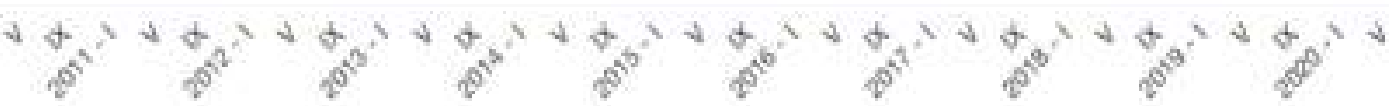

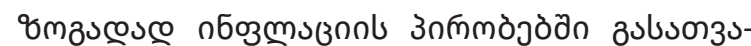

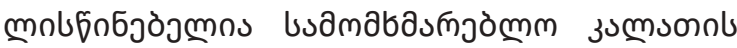

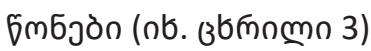

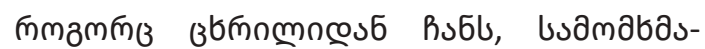

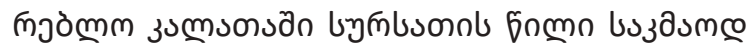

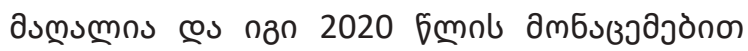




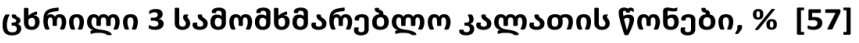

\begin{tabular}{|c|c|c|c|c|c|c|c|c|c|c|}
\hline \multirow{3}{*}{$\mathrm{N}$} & \multirow{2}{*}{ 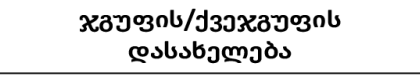 } & \multicolumn{9}{|c|}{ 6jmo } \\
\hline & & 2012 & 2013 & 2014 & 2015 & 2016 & 2017 & 2018 & 2019 & 2020 \\
\hline & bym & $100 \%$ & $100 \%$ & $100 \%$ & $100 \%$ & $100 \%$ & $100 \%$ & $100 \%$ & $100 \%$ & $100 \%$ \\
\hline 1 & 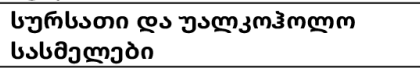 & $30,32 \%$ & $30,69 \%$ & $30,25 \%$ & $30,74 \%$ & $31,10 \%$ & $30,09 \%$ & $30,29 \%$ & $30,76 \%$ & $31,27 \%$ \\
\hline 2 & பyற̆bson & $27,45 \%$ & $28,01 \%$ & $27,37 \%$ & $27,95 \%$ & $27,83 \%$ & $26,92 \%$ & $26,86 \%$ & $27,27 \%$ & $28,03 \%$ \\
\hline 3 & 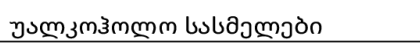 & $2,87 \%$ & $2,68 \%$ & $2,88 \%$ & $2,79 \%$ & $3,27 \%$ & $3,17 \%$ & $3,42 \%$ & $3,49 \%$ & $3,24 \%$ \\
\hline 4 & 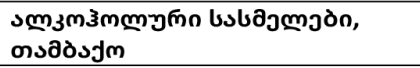 & $5,50 \%$ & $5,36 \%$ & $5,08 \%$ & $5,19 \%$ & $6,02 \%$ & $6,39 \%$ & $6,72 \%$ & $6,61 \%$ & $6,39 \%$ \\
\hline 5 & 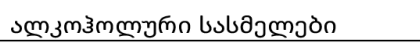 & $2,16 \%$ & $2,64 \%$ & $2,19 \%$ & $2,03 \%$ & $3,18 \%$ & $3,50 \%$ & $3,43 \%$ & $3,61 \%$ & $3,54 \%$ \\
\hline 6 & 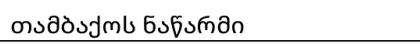 & $3,33 \%$ & $2,71 \%$ & $2,89 \%$ & $2,93 \%$ & $2,84 \%$ & $2,90 \%$ & $3,29 \%$ & $3,01 \%$ & $2,85 \%$ \\
\hline 7 & 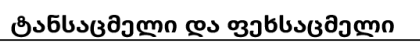 & $2,65 \%$ & $2,58 \%$ & $2,87 \%$ & $2,86 \%$ & $3,13 \%$ & $3,35 \%$ & $3,56 \%$ & $3,72 \%$ & $3,92 \%$ \\
\hline 8 & 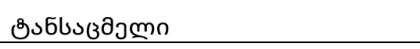 & $1,79 \%$ & $1,75 \%$ & $2,01 \%$ & $1,98 \%$ & $2,23 \%$ & $2,27 \%$ & $2,42 \%$ & $2,49 \%$ & $2,40 \%$ \\
\hline 9 & озбьлзалмп & $0,86 \%$ & $0,82 \%$ & $0,86 \%$ & $0,87 \%$ & $0,90 \%$ & $1,08 \%$ & $1,15 \%$ & $1,22 \%$ & $1,51 \%$ \\
\hline 10 & 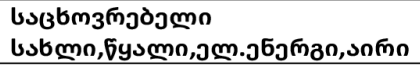 & $8,23 \%$ & $8,78 \%$ & $8,38 \%$ & $8,48 \%$ & $8,24 \%$ & $8,38 \%$ & $8,49 \%$ & $8,77 \%$ & $9,04 \%$ \\
\hline 11 & 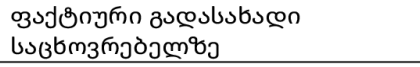 & $0,90 \%$ & $1,07 \%$ & $1,11 \%$ & $1,15 \%$ & 1,19\% & $1,15 \%$ & $1,06 \%$ & $1,14 \%$ & $1,56 \%$ \\
\hline 12 & 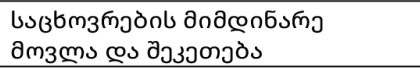 & $0,93 \%$ & $0,78 \%$ & $0,87 \%$ & $0,85 \%$ & 0,98\% & $0,91 \%$ & $0,96 \%$ & 1,12\% & $1,18 \%$ \\
\hline 13 & 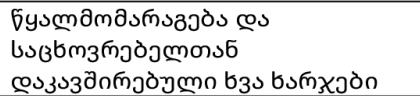 & $1,03 \%$ & $1,50 \%$ & $0,94 \%$ & $1,36 \%$ & $1,12 \%$ & 0,99\% & $0,98 \%$ & $0,95 \%$ & $1,00 \%$ \\
\hline 14 & 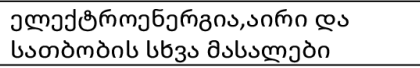 & $5,38 \%$ & $5,43 \%$ & $5,46 \%$ & $5,12 \%$ & $4,95 \%$ & $5,33 \%$ & $5,49 \%$ & $5,56 \%$ & $5,29 \%$ \\
\hline 15 & 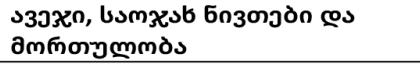 & $5,07 \%$ & $4,80 \%$ & $6,21 \%$ & $6,43 \%$ & $6,40 \%$ & $6,56 \%$ & $6,35 \%$ & $6,45 \%$ & $5,94 \%$ \\
\hline 16 & 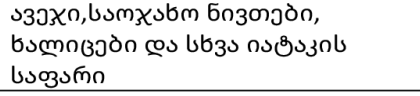 & $0,34 \%$ & $0,34 \%$ & $0,56 \%$ & $0,91 \%$ & $0,82 \%$ & $0,80 \%$ & $0,70 \%$ & $0,82 \%$ & $0,70 \%$ \\
\hline 17 & 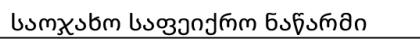 & $0,09 \%$ & $0,10 \%$ & $0,13 \%$ & $0,12 \%$ & $0,14 \%$ & $0,16 \%$ & $0,14 \%$ & $0,12 \%$ & $0,13 \%$ \\
\hline 18 & 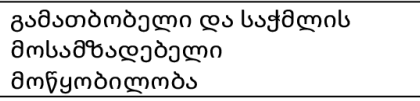 & $1,99 \%$ & $1,81 \%$ & $2,57 \%$ & $2,29 \%$ & $2,32 \%$ & $2,52 \%$ & $2,36 \%$ & $2,13 \%$ & $1,71 \%$ \\
\hline 19 & 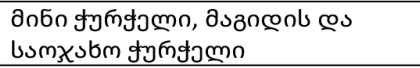 & $0,70 \%$ & $0,68 \%$ & $0,73 \%$ & $0,72 \%$ & $0,80 \%$ & $0,73 \%$ & $0,70 \%$ & $0,71 \%$ & $0,82 \%$ \\
\hline 20 & 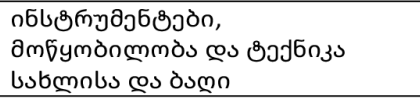 & $0,07 \%$ & $0,02 \%$ & $0,04 \%$ & $0,04 \%$ & $0,07 \%$ & $0,08 \%$ & $0,07 \%$ & $0,07 \%$ & $0,05 \%$ \\
\hline 21 & 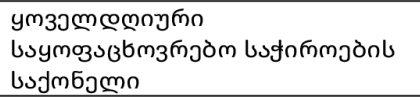 & $1,88 \%$ & $1,85 \%$ & $2,18 \%$ & $2,35 \%$ & $2,26 \%$ & $2,26 \%$ & $2,38 \%$ & $2,55 \%$ & $2,54 \%$ \\
\hline 22 & 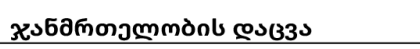 & $7,54 \%$ & $9,04 \%$ & $10,09 \%$ & $9,46 \%$ & $9,81 \%$ & $8,42 \%$ & $8,61 \%$ & $8,02 \%$ & $8,84 \%$ \\
\hline 23 & 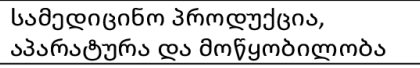 & $2,87 \%$ & $3,45 \%$ & $2,38 \%$ & $2,49 \%$ & $2,60 \%$ & $2,84 \%$ & $3,01 \%$ & $3,19 \%$ & $3,42 \%$ \\
\hline 24 & 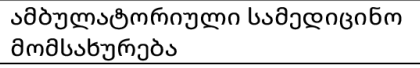 & $2,44 \%$ & $2,48 \%$ & $4,00 \%$ & $3,85 \%$ & $3,49 \%$ & $2,80 \%$ & $2,85 \%$ & $2,30 \%$ & $2,19 \%$ \\
\hline 25 & 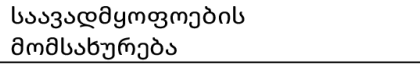 & $2,23 \%$ & $3,11 \%$ & $3,71 \%$ & $3,11 \%$ & $3,72 \%$ & $2,78 \%$ & $2,75 \%$ & $2,53 \%$ & $2,22 \%$ \\
\hline 26 & 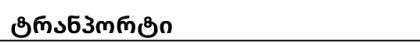 & $12,76 \%$ & $12,74 \%$ & $11,82 \%$ & $11,80 \%$ & $12,10 \%$ & $13,12 \%$ & $12,60 \%$ & $12,14 \%$ & $12,06 \%$ \\
\hline 27 & 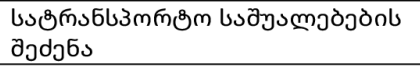 & $0,96 \%$ & $0,87 \%$ & $0,86 \%$ & $0,74 \%$ & $0,73 \%$ & $0,96 \%$ & $0,88 \%$ & $0,89 \%$ & $0,89 \%$ \\
\hline 28 & 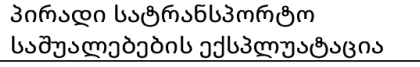 & $7,98 \%$ & $8,52 \%$ & $7,75 \%$ & $7,89 \%$ & $7,85 \%$ & $8,46 \%$ & $8,21 \%$ & $7,94 \%$ & $7,85 \%$ \\
\hline 29 & 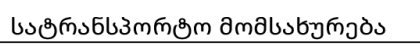 & $3,82 \%$ & $3,35 \%$ & $3,21 \%$ & $3,17 \%$ & $3,53 \%$ & $3,69 \%$ & $3,50 \%$ & $3,30 \%$ & $3,32 \%$ \\
\hline 30 & 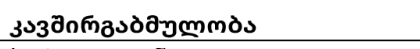 & $5,60 \%$ & $4,09 \%$ & $3,61 \%$ & $3,61 \%$ & $3,24 \%$ & $3,69 \%$ & $3,90 \%$ & $3,58 \%$ & $3,81 \%$ \\
\hline 31 & 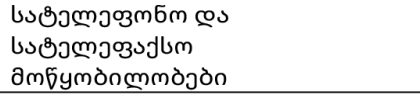 & $0,02 \%$ & $0,04 \%$ & $0,04 \%$ & $0,89 \%$ & $0,03 \%$ & $0,69 \%$ & $0,83 \%$ & $0,70 \%$ & $0,82 \%$ \\
\hline 32 & 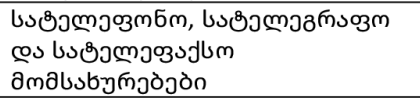 & $5,57 \%$ & $4,05 \%$ & $3,57 \%$ & $2,72 \%$ & $3,21 \%$ & $3,00 \%$ & $3,07 \%$ & $2,88 \%$ & $2,99 \%$ \\
\hline 33 & 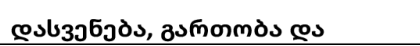 & $6,82 \%$ & $6,73 \%$ & $6,56 \%$ & $7,11 \%$ & $6,15 \%$ & $6,36 \%$ & $5,77 \%$ & $5,65 \%$ & $3,82 \%$ \\
\hline
\end{tabular}




\begin{tabular}{|c|c|c|c|c|c|c|c|c|c|c|}
\hline & 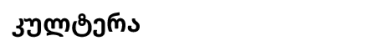 & & & & & & & & & \\
\hline 34 & 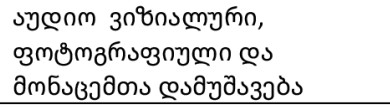 & $0,86 \%$ & $0,84 \%$ & $0,72 \%$ & $0,78 \%$ & $1,19 \%$ & $1,22 \%$ & $1,24 \%$ & $0,66 \%$ & $0,51 \%$ \\
\hline 35 & 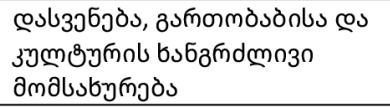 & $\ldots$ & $\ldots$ & $0,23 \%$ & $0,02 \%$ & $0,01 \%$ & $0,04 \%$ & $0,04 \%$ & $0,02 \%$ & $0,01 \%$ \\
\hline 36 & 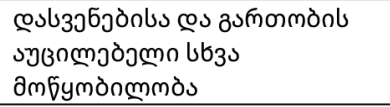 & $0,67 \%$ & $0,14 \%$ & $0,21 \%$ & $0,24 \%$ & $0,11 \%$ & $0,53 \%$ & $0,48 \%$ & $0,28 \%$ & $0,36 \%$ \\
\hline 37 & 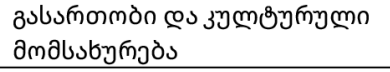 & $3,25 \%$ & $4,20 \%$ & $4,55 \%$ & $4,31 \%$ & $2,99 \%$ & $2,63 \%$ & $2,91 \%$ & $0,83 \%$ & $0,88 \%$ \\
\hline 38 & 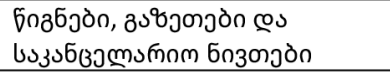 & $2,04 \%$ & $1,55 \%$ & $0,84 \%$ & $1,76 \%$ & $1,86 \%$ & $1,93 \%$ & $1,81 \%$ & $0,92 \%$ & $0,97 \%$ \\
\hline 39 & 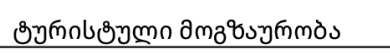 & $\ldots$ & $\ldots$ & $\ldots .$. & $\ldots .$. & $\ldots$ & $\ldots .$. & $\ldots .$. & $2,94 \%$ & $1,08 \%$ \\
\hline 40 & aدбงommjòs & $6,07 \%$ & $4,87 \%$ & $5,42 \%$ & $5,03 \%$ & $4,98 \%$ & $4,70 \%$ & $4,61 \%$ & $5,00 \%$ & $5,00 \%$ \\
\hline 41 & 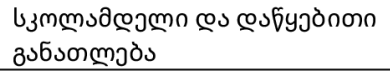 & $0,29 \%$ & $0,34 \%$ & $0,34 \%$ & $0,34 \%$ & $0,33 \%$ & $0,30 \%$ & $0,32 \%$ & $0,38 \%$ & $0,32 \%$ \\
\hline 42 & 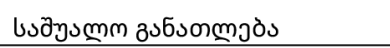 & $1,73 \%$ & $2,04 \%$ & $0,34 \%$ & $2,21 \%$ & $2,14 \%$ & $2,01 \%$ & $2,09 \%$ & $2,20 \%$ & $2,23 \%$ \\
\hline 43 & 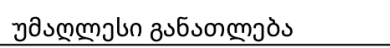 & $3,84 \%$ & $2,42 \%$ & $2,67 \%$ & $2,43 \%$ & $2,35 \%$ & $2,33 \%$ & $2,15 \%$ & $2,36 \%$ & $2,40 \%$ \\
\hline 44 & 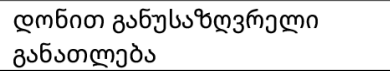 & $0,21 \%$ & $0,07 \%$ & $0,07 \%$ & $0,06 \%$ & $0,15 \%$ & $0,06 \%$ & $0,06 \%$ & $0,06 \%$ & $0,06 \%$ \\
\hline 45 & 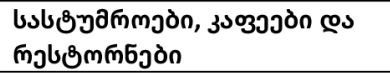 & $4,40 \%$ & $5,23 \%$ & $4,96 \%$ & $4,80 \%$ & $4,01 \%$ & $4,06 \%$ & $4,04 \%$ & $4,03 \%$ & $5,40 \%$ \\
\hline 46 & 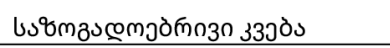 & $4,16 \%$ & $4,90 \%$ & $4,64 \%$ & $4,42 \%$ & $3,60 \%$ & $3,69 \%$ & $3,65 \%$ & $3,66 \%$ & $4,87 \%$ \\
\hline 47 & 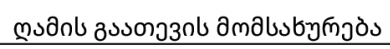 & $0,25 \%$ & $0,32 \%$ & $0,32 \%$ & $0,37 \%$ & $0,41 \%$ & $0,37 \%$ & $0,39 \%$ & $0,37 \%$ & $0,53 \%$ \\
\hline 48 & 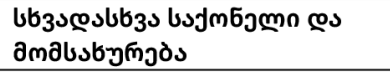 & $5,04 \%$ & $5,09 \%$ & $4,74 \%$ & $4,50 \%$ & $4,80 \%$ & $4,88 \%$ & $5,07 \%$ & $5,28 \%$ & $5,50 \%$ \\
\hline 49 & 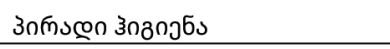 & $2,10 \%$ & $2,07 \%$ & $1,68 \%$ & $1,66 \%$ & $1,70 \%$ & $1,76 \%$ & $2,01 \%$ & $2,11 \%$ & $2,15 \%$ \\
\hline 50 & 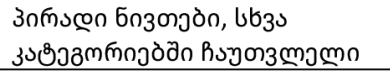 & $0,63 \%$ & $0,65 \%$ & $0,73 \%$ & $0,72 \%$ & $0,67 \%$ & $0,68 \%$ & $0,65 \%$ & $0,71 \%$ & $0,64 \%$ \\
\hline 51 & 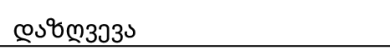 & $0,82 \%$ & $0,73 \%$ & $0,86 \%$ & $0,56 \%$ & $0,58 \%$ & $0,51 \%$ & $0,51 \%$ & $0,51 \%$ & $0,55 \%$ \\
\hline 52 & 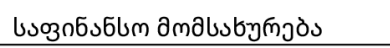 & $0,79 \%$ & $0,96 \%$ & $0,83 \%$ & $0,84 \%$ & $1,22 \%$ & $1,38 \%$ & $1,37 \%$ & $1,40 \%$ & $1,50 \%$ \\
\hline 53 & ub3s bubnu amabsbymjòs & $0,70 \%$ & $0,69 \%$ & $0,64 \%$ & $0,73 \%$ & $0,64 \%$ & $0,55 \%$ & $0,52 \%$ & $0,55 \%$ & $0,66 \%$ \\
\hline
\end{tabular}

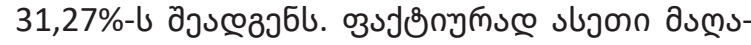

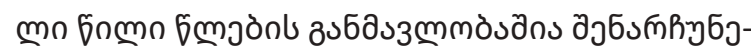

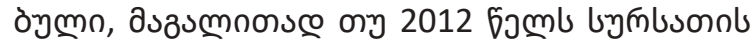

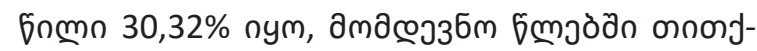

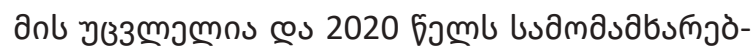

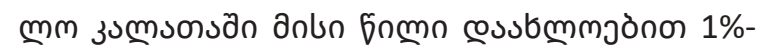

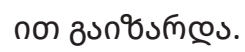

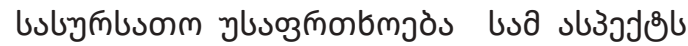

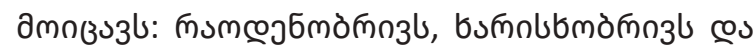

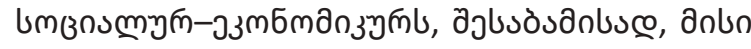

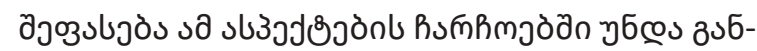

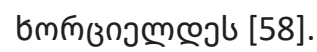

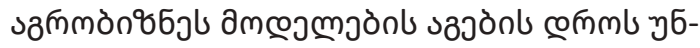

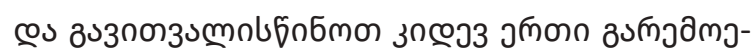

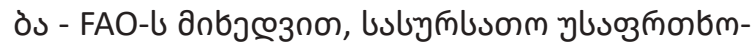

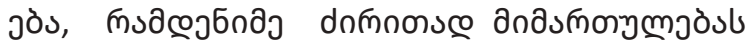

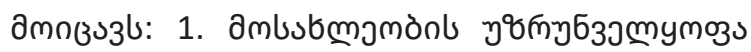

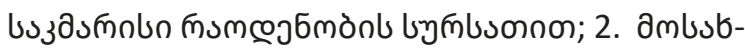

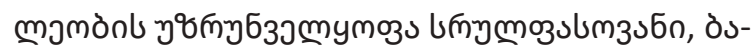

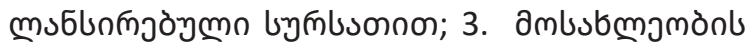

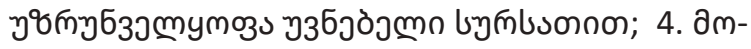

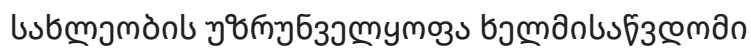
bymbsonon.

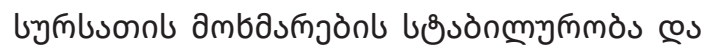

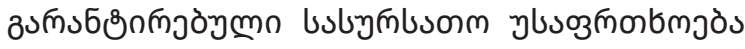

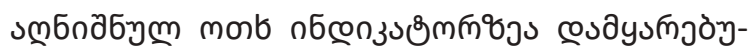

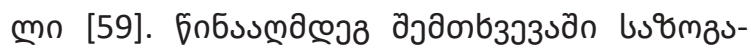

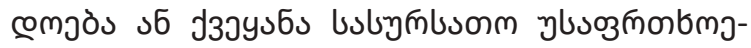

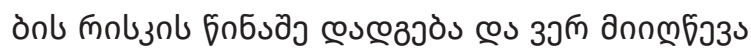

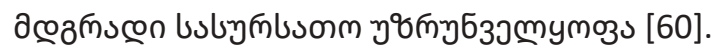




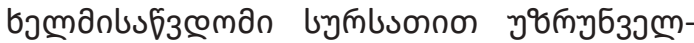

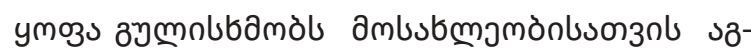

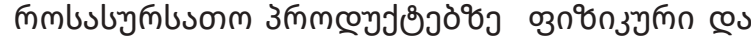

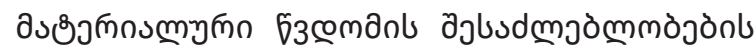

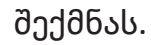

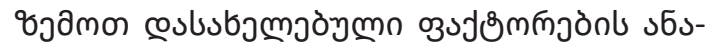

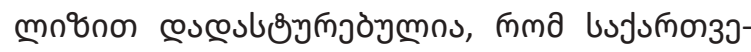

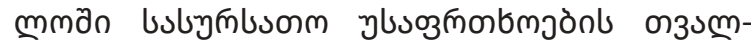

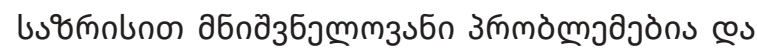

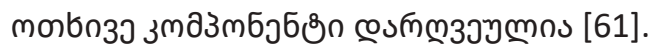

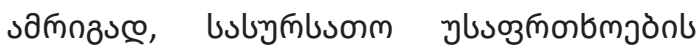

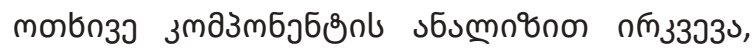

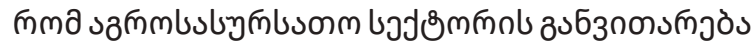

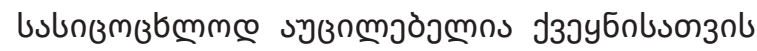

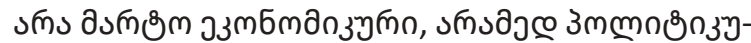

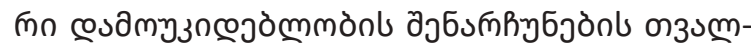

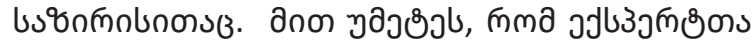

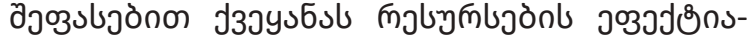

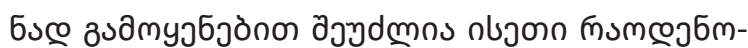

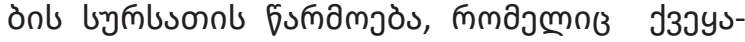

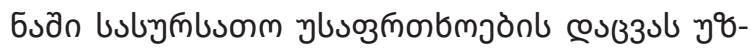

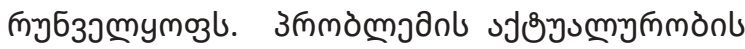

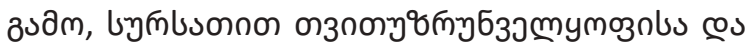

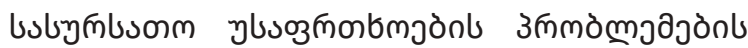

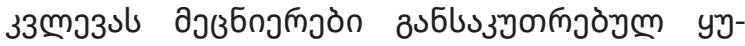

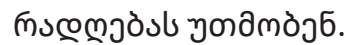

\section{cSL336s}

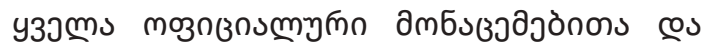

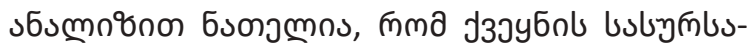

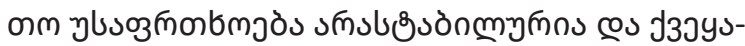

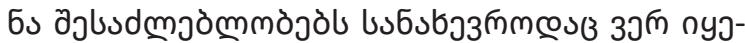

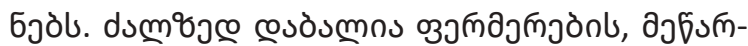

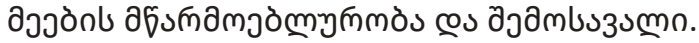

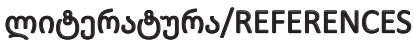

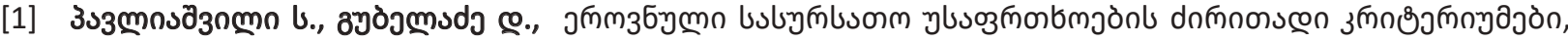
2014, https://for.ge/view/36048/erovnuli-sasursaTo-usafrTxoebis-ZiriTadi-kriteriumebi.html

[2] Ekanemıa, Mafuyaib, Clardy, 2016 pg 58

[3] FAO, 2017:46.

[4] Nsiah C., Wallace B., Trends in Agricultural Production Efficiency and Its Implications for Food Security in SubSaharan African Countries. 2017

[5] International http://agrofor.ues.rs.ba/paper.php?id=54

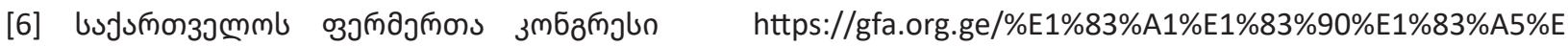
1\%83\%90\%E1\%83\%A0\%E1\%83\%97\%E1\%83\%95\%E1\%83\%94\%E1\%83\%9A\%E1\%83\%9D\%E1\%83\%A1\%E1\%83\%A4\%E1\%83\%94\%E1\%83\%A0\%E1\%83\%9B\%E1\%83\%94\%E1\%83\%A0\%E1\%83\%97\%E1\%83\%90\%Е1\%83\%99\%E1\%83\%9D\%E1\%83\%9C/

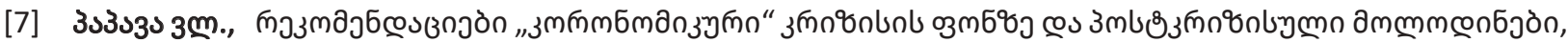

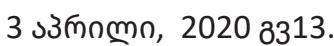

[8] World Food Summit 1996 Food Security, http://www.fao.org/fileadmin/templates/faoitaly/documents/pdf/ pdf_Food_Security_Cocept_Note.pdf

[9] Prof. Pasquale De Muro., Prof. Matteo Mazziotta., Towards a Food Insecurity Multidimensional Index (FIMI) 2010/2011 http://www.fao.org/fileadmin/templates/ERP/uni/FIMI.pdf

[10] Blazhekovik j., Dimovska D., Stojanovski S., Food safety management - A practical guide for the food industry, 2014. https://www.researchgate.net/publication/283734184_Food_safety_management_-_A_practical_ guide_for_the_food_industry

[11] Clayton Campanhola C., Pandey S., Sustainable Food and Agriculture, FAO \& Elsevier's Academic Press, Rome, 2019. https://www.elsevier.com/books/sustainable-food-and-agriculture/campanhola/978-0-12-812134-4

[12] Kharaishvili E., ErkomaiSvili G., Chavleishvili M., Problems Faced by the Agricultural Sector and Agribusiness Development Strategy in Georgia, International Science Index 107, International Journal of Social, Behavioral, Educational, Economic and Management Engineering, 9(11), 2015. 


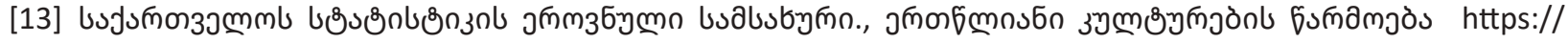
www.geostat.ge/ka/modules/categories/196/soflis-meurneoba

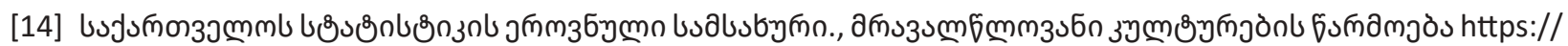
www.geostat.ge/ka/modules/categories/196/soflis-meurneoba

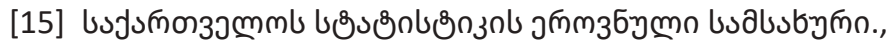
bmm̧nl fuñamjòs https://www.geostat.ge/ka/modules/categories/196/soflis meurneoba

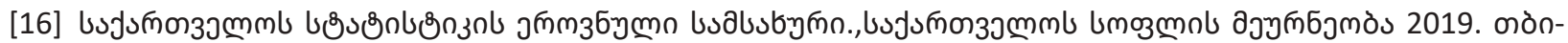
molon 20203334

[17] bujง Emòs https://www.geostat.ge/ka/modules/categories/196/soflis-meurneoba

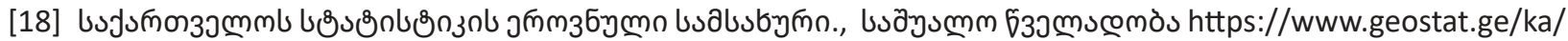
modules/categories/196/soflis-meurneoba

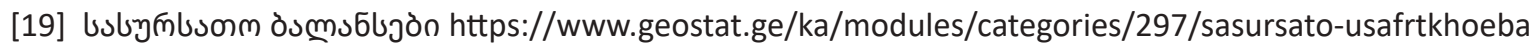

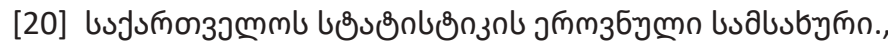
uýnbsonol fumamjòs https://www.geostat.ge/ka/modules/categories/297/sasursato-usafrtkhoeba

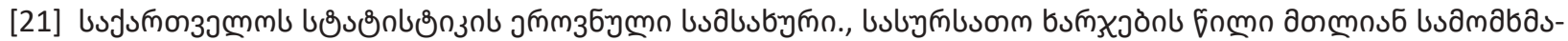

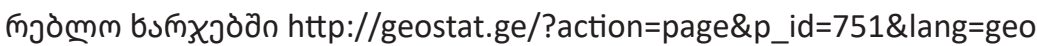

[22] Agriculture of Georgia 2018, NATIONAL STATISTICS OFFICE OF GEORGIA , TBILISI, 2019, 33. 19.

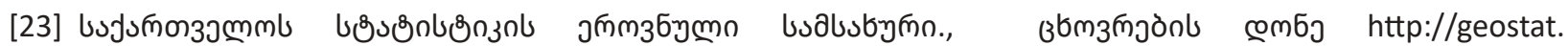
ge/?action=page\&p_id=187\&lang=geo

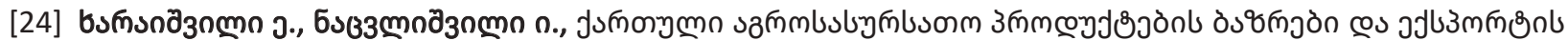

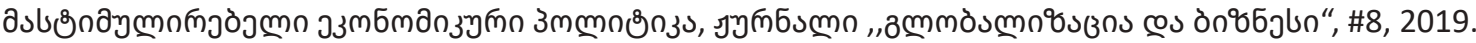

[25] Kharaishvili E., Diversification of Agribusiness and Rural Development Models in Georgia, IV International Scientific and Practical Conference "Strategic Imperatives of Modern Management," 19-20 April, 2018. http:// ir.kneu.edu.ua/bitstream/2010/24417/1/5348.pdf

[26] KharaiSvili E., Challenges for sustainable food security in Georgia, XV EAAE Congress in Parma: Towards Sustainable Agri-Food Systems: Balancing between Markets and Society, Parma, Italy, 29 August -1 September 2017. https://www.researchgate.net/publication/319979747_Challenges_for_sustainable_food_security_in_ Georgia

[27] Kharaishvili, E., Gechbaia B., Mamuladze G. VEGETABLE MARKET: COMPETITIVE ADVANTAGES OF GEORGIAN PRODUCT AND COMPETITION CHALLENGES, Innovative Marketing, Volume 14, Issue 3, 2018. Volume 14 2018, Issue \#3, pp. 8-16.

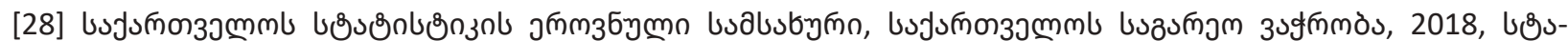

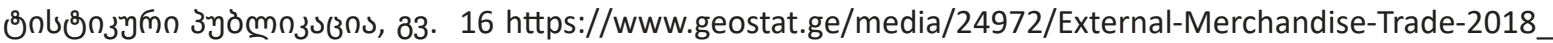
publication.pdf

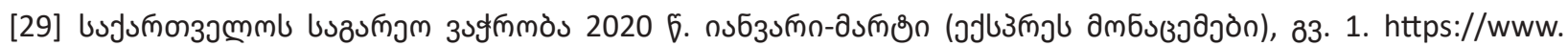
geostat.ge/media

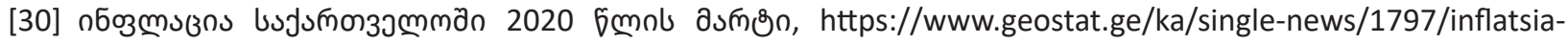
sakartveloshi-2020-tslis-marti

[31] Erkomaisvili G., Trends In The Development Of Cooperatives And The Policies For Sustainable Development Of Agriculture In Georgia. International Research Conferences Modern marine technologies, problems of socioeconomic development and solutions. Batumi-Georgia, June 24, 2017.

[32] Karyn A Havas, Karyn A Havas, Food security: its components and challenges, January 2011 nternational Journal of Food Safety Nutrition and Public Health 4(1):4 - 11.

[33] FAO Policy Priorities for Food Security, http://www.fao.org/fileadmin/templates/faoitaly/documents/pdf/pdf_ Food_Security_Cocept_Note.pdf 


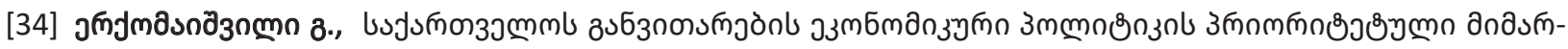

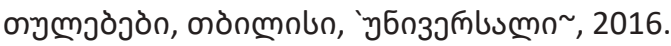

[35] WORLD PROGRAMME FOR THE CENSUS OF AGRICULTURE 2020, VOLUME 1 Programme, concepts and definitions, FOOD AND AGRICULTURE ORGANIZATION OF THE UNITED NATIONS Rome, 2017 https://www. geostat.ge/media/19735/World-Programme-for-the-Census-of-Agriculture-2020.pdf

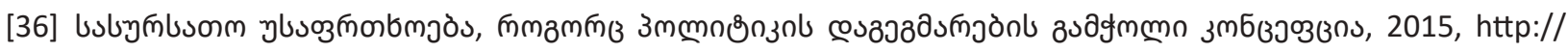
enpard.ge/ge/food-security-as-a-crosscutting-concept-for-policy-making-in-georgia/

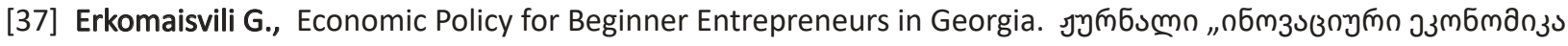
œu పsmo3s", №3, 2018

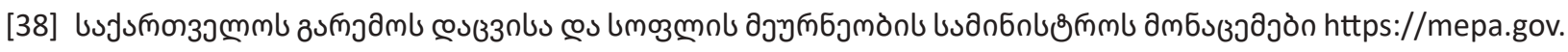
ge/Ge/News/Details/17911

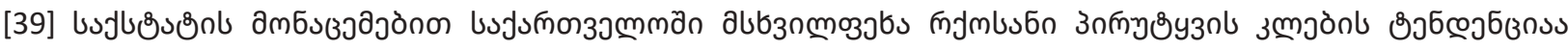
http://georgiandairy.org/ka/post/sakstatis-monatsemebit-sakartveloshi-mskhvilpekha-rkosani-pirutqvisklebis-tendentsiaa

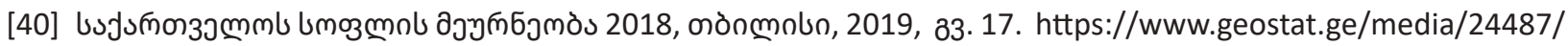
soflis-meurneoba_2018.pdf

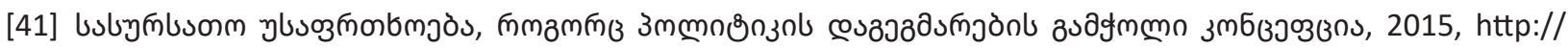
enpard.ge/ge/food-security-as-a-crosscutting-concept-for-policy-making-in-georgia/

[42] Eter Kharaishvili, Badri Gechbaia, Gela Mamuladze, Vegetable market: competitive advantages of Georgian product and competition challenges, Journal Innovative Marketing, Issue \#3. https://businessperspectives.org/ journals/innovative-marketing/issue-296/vegetable-market-competitive-advantages-of-georgian-product-andcompetition-challenges

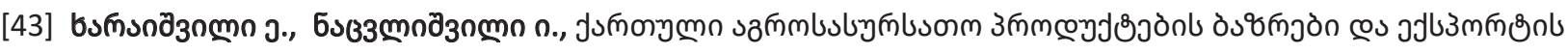

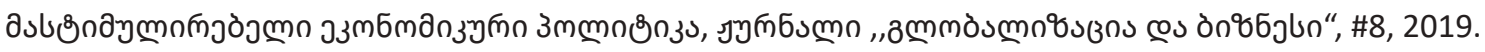

[44] http://geostat.ge/?action=page\&p_id=751\&lang=geo

[45] Kharaishvili E. (2017) Challenges for sustainable food security in Georgia, XV EAAE Congress in Parma: Towards Sustainable Agri-Food Systems: Balancing between Markets and Society, Parma, Italy, 29 August - 1 September 2017.

[46] https://www.geostat.ge/ka/modules/categories/637/eksporti

[47] https://www.geostat.ge/ka/modules/categories/637/eksporti

[48] https://www.geostat.ge/ka/modules/categories/637/eksporti

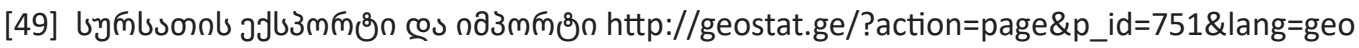

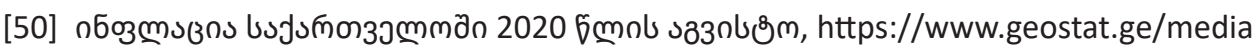

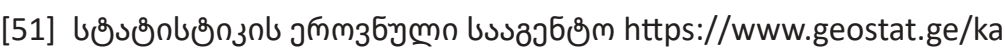

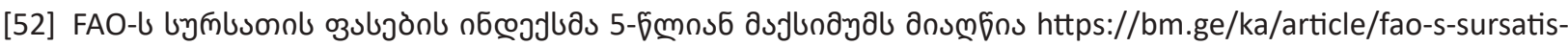
fasebis-indeqsma-5-wlian-maqsimums-miagwia-/46739/https://bm.ge/ka/article/fao-s-sursatis-fasebisindeqsma-5-wlian-maqsimums-miagwia-/46739/https://bm.ge/ka/article/fao-s-sursatis-fasebis-indeqsma-5wlian-maqsimums-miagwia-/46739/

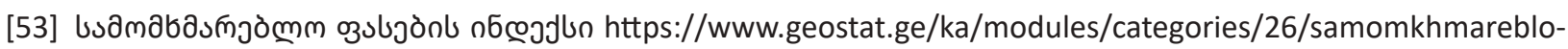
fasebis-indeksi-inflatsia

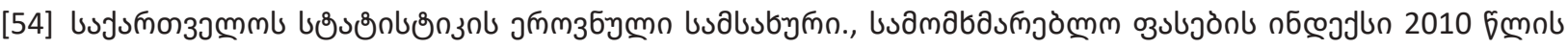

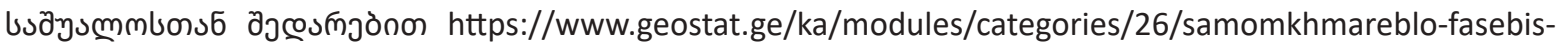

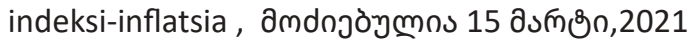

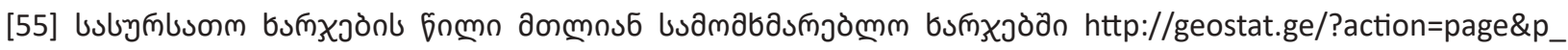
id=751\&lang=geo

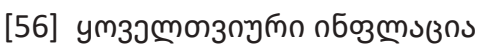


https://www.geostat.ge/ka/modules/categories/26/samomkhmareblo-fasebis-indeksi-inflatsia

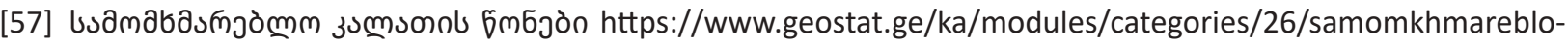
fasebis-indeksi-inflatsia

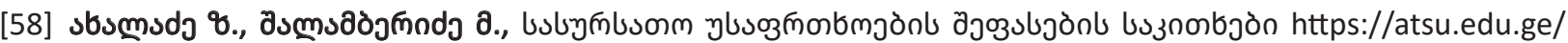
EJournal/BLSS2015/eJournal/Papers/AkhaladzeZeinab.pdf

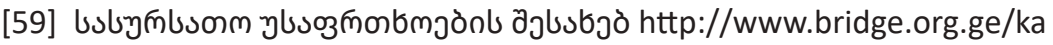

[60] Kharaishvili E. Challenges for sustainable food security in Georgia, XV EAAE Congress in Parma: Towards Sustainable Agri-Food Systems: Balancing between Markets and Society, Parma, Italy, 29 August - 1 September 2017

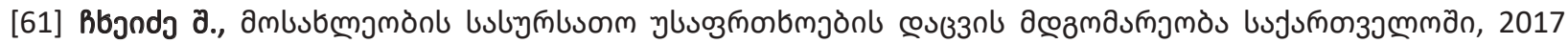
http://agronews.ge/mosakhleobis-sasursatho-usaphrthkhoebis-datsvis-mdgomareoba-saqarthveloshi/ 